\title{
DOCUMENTOS
}




\section{LA MIGRACION DE PROFESIONALES COLOMBIANOS AL EXTERIOR}

\section{Estadística sobre la migración de profesionales} y él empleo de extranjeros

"La fuga de cerebros", es una expresión nueva e impactante que se utiliza para identificar la migración de la capacidad de trabajo profesional de los países pobres a los países más ricos. El concepto abarca apenas una parte de la pérdida de talentos en los países en vía de desarrollo. Las naciones desarrolladas, opinan que la migración de la fuerza de trabajo profesional, se debe a las debilidades estructurales en las economías en vía de desarrollo y éstas a su turno han comenzado a levantar su voz, afirmando que hay competencia desleal en el mercado de trabajo internacional. Quienes han expresado su inquietud sobre la migración del talento, hacia los países desarrollados, automáticamente asocian el problema, a los estudiantes que viajan al exterior a mejorar su formación. Se asimilan la migración de los estudiantes sobresalientes, con quienes lo hacen sin motivo; suposición que puede perjudicar el futuro de la especialización en el extranjero. Por lo tanto, se debe analizar el problema migratorio, bajo tres aspectos:

a) El flujo de estudiantes universitarios y post-graduados a las naciones desarrolladas para conseguir una formación avanzada, no disponible en su país, o de una mejor calidad o definitivamente diferente;

b) El flujo de profesionales que deciden emigrar de sus países de origen; y

c) El flujo de la fuerza de trabajo de alto nivel que emigra de los países más ricos a los países más pobres, lo cual hasta cierto punto, sirve de contra peso a las pérdidas humanas causadas por la emigración de las nacionales.

\section{A. Estudiantes Colombianos que salen a Estudiar a los Países Desarrollados}

Desde 1950, Colombia ha establecido su propio programa de ayuda económica, para apoyar a los estudiantes universitarios y post-graduados. Que toman cursos avanzados en el exterior y desean estar al día por lo que toca a ideas y conceptos nuevos en el campo cultural, científico y tecnológico.

ICETEX (Instituto Colombiano de Estudios Técnicos en el Exterior), ofreciendo préstamos a largo plazo con bajos intereses, transformó el sistema tradicional de becas en un fondo rotatorio, que ha financiado la formación del $26 \%$ de los profesionales Colombianos, tanto dentro como fuera del país. El programa ICETEX es conocido mundialmente y ha servido como programa piloto para otras naciones de América Latina, como Venezuela, Perú, Panamá, República Dominicana y recientemente, Argentina. Hasta los Estados Unidos, se inspiró en ICETEX, para redactar el Acta de Defensa Nacional educativa en 1957 en donde se fijan los estatutos para los préstamos estudiantiles.

Cada estudiante colombiano que desea viajar al exterior para adquirir educación superior, puede solicitar los servicios de ICETEX, a saber: 
a) Prestamos a largo plazo para los estudios de post-grado en el exterior;

b) Becas de gobiernos extranjeros con el mismo propósito. Actuando el Instituto en este caso como un centro distribuidor y administrador.

c) La autorización de giro en Moneda extranjera para quienes poseen sus propios recursos económicos. Este último punto, se debe al hecho de que el país tiene una política especial sobre el giro de divisas.

\section{Cuadro No. 1}

\section{ESTUDIANTES COLOMBIANOS EN EL EXTERIOR}

\begin{tabular}{rcc}
\hline año & $\begin{array}{c}\text { Número de estudiantes } \\
\text { en el exterior }\end{array}$ & $\begin{array}{c}\text { \% del total de estudiantes } \\
\text { universitarios en el país }\end{array}$ \\
\hline 1955 & $101^{18}$ & 071 \\
1956 & 2.467 & 14.9 \\
1957 & 907 & 5.1 \\
1958 & 603 & 3.8 \\
1959 & 964 & 4.9 \\
1960 & 617 & 2.8 \\
1961 & 2.602 & 8.3 \\
1962 & 1.179 & 3.0 \\
1963 & 972 & 2.0 \\
19.64 & 1.024 & 2.8 \\
1965 & 1.973 & 4.6 \\
1966 & 2.724 & 5.6 \\
1967 & 1.779 & 2.5 \\
1968 & 1.091 & 1.8 \\
TOTAL: & 19.003 & 4.8 \\
\hline
\end{tabular}

Fuente: ICETEX.

A través de estos servicios, se presume que mas de $90 \%$ de los estudiantes colombianos que viajan al exterior, se deben haber registrado en el ICETEX.

De 1955 a 1968, 19.003 estudiantes colombianos, viajaron al exterior bajo los auspicios de ICETEX, para emprender estudios que se han considerado de importancia vital para las necesidades del país. Esta cifra representa el $48 \%$ del total de los graduados colombianos, educados en Institutos Nacionales de Educación Superior, Cuadro No. 1. Esta cifra representa un promedio de 1.355 de jóvenes que estudian en el exterior anualmente.

De los 19.003 estudiantes que recibieron educación en el exterior, el $20.2 \%$, fueron financiados con prestamos de ICETEX; el 15\% recibieron becas de gobiernos extranjeros,

\footnotetext{
${ }^{18}$ Los datos para 1955 no incluyen a los estudiantes financiados por sus familias. 
organizaciones internacionales, fundaciones privadas, etc., y las propias familias financiaron el $64 \%$. Además, el $83.3 \%$ salieron a países más desarrollados y el $16.7 \%$ a países en vía de desarrollo, tal como se presenta en el Cuadro No. 2.

El país que más atrajo estudiantes colombianos, fue Estados Unidos con el $41.2 \%$, debido al grado de desarrollo científico y tecnológico de este país y a las facilidades educativas disponibles para los extranjeros. Siguen a continuación, España, con el 13.4\%; Italia, con el 7.3\%; Francia, con el 7.00\%; Alemania, con el 6.6\%; Bélgica, con el 4.4\%; e Inglaterra, con el $3.5 \%$.

Los países en vía de desarrollo que atraen a los estudiantes colombianos son en su orden:

México, Argentina y Chile. Pero América Latina en conjunto, tan solo representa aproximadamente el $8 \%$ de la cifra total.

Los estudiantes colombianos que tuvieron oportunidad de tener entrenamiento avanzado en el exterior pertenecían a todas las áreas del conocimiento, segün la política gubernamental de desarrollar los recursos humanos en una forma armoniosa. En el Cuadro No. 3 se presenta esta composición.

Es importante anotar que las profesiones con mayor demanda de especialización en el exterior, fueron los siguientes: Las ciencias sociales, con el 16.6\%; las ciencias médicas, con el $14.7 \%$; educación, con el $10.7 \%$; y las ciencias naturales y aplicados, con el $10.6 \%$. En cambio las carreras como el derecho, las humanidades y las artes liberales, que antes atraían a los colombianos, conformando al país dentro de ciertas características especiales, están ahora disminuyendo cuantitativamente. Aunque solo un pequeño porcentaje de los estudiantes han adelantado carreras intermedias en el exterior, es importante tenerlas en cuenta, ya que el país empieza a desarrollar estos programas.

Se puede observar que cada cinco años se registra un aumento considerable en el número de estudiantes colombianos que estudian en el exterior.

\section{Cuadro No. 2 \\ ESTUDIANTES COLOMBIANOS EN EL EXTERIOR SEGÚN PAIS DONDE ESTUDIAN}

\begin{tabular}{|c|c|c|c|c|c|c|c|c|c|c|c|c|c|c|c|c|}
\hline Países & 1955 & 1956 & 1957 & 1958 & 1959 & 1960 & 1961 & 1962 & 1963 & 1964 & 1965 & 1966 & 1967 & 1968 & Total & \%Total \\
\hline \multicolumn{17}{|c|}{$\begin{array}{l}\text { A. Países } \\
\text { desarrollados }\end{array}$} \\
\hline Estados Unidos & 40 & 1.086 & 362 & 241 & 386 & 247 & 1.154 & 485 & 389 & 364 & 829 & 1.178 & 476 & 588 & 7.825 & 41.18 \\
\hline España & 13 & 326 & 120 & 80 & 127 & 81 & 460 & 155 & 128 & 126 & 301 & 407 & 135 & 83 & 2.542 & 13.38 \\
\hline Francia & 7 & 142 & 65 & 43 & 69 & 44 & 151 & 85 & 70 & 104 & 116 & 160 & 182 & 83 & 1.321 & 6.95 \\
\hline Italia & 7 & 175 & 64 & 43 & 69 & 44 & 205 & 100 & 80 & 130 & 160 & 210 & 40 & 65 & 1.392 & 7.32 \\
\hline Alemania & 7 & 168 & 62 & 41 & 66 & 42 & 103 & 80 & 66 & 58 & 99 & 170 & 230 & 55 & 1.247 & 6.56 \\
\hline Inglaterra & 4 & 91 & 34 & 22 & 36 & 23 & 78 & 44 & 36 & 18 & 73 & 90 & 83 & 38 & 670 & 3.53 \\
\hline Bélgica & 5 & 113 & 42 & 28 & 44 & 28 & 75 & 38 & 34 & 16 & 71 & 93 & 207 & 39 & 833 & 4.38 \\
\hline Sub- total & 83 & 2.101 & 749 & 498 & 797 & 509 & 2.226 & 987 & 803 & 816 & 1.649 & 2.308 & 1.353 & 951 & 15.830 & 83.30 \\
\hline$\%$ & 0.50 & 13.48 & 4.11 & 3.23 & 5.00 & 3.34 & 14.48 & 6.30 & 5.01 & 5.14 & 9.52 & 14.91 & 8.86 & 6.12 & $100 \%$ & \\
\hline \multirow{2}{*}{\multicolumn{17}{|c|}{$\begin{array}{l}\text { B. Países en vía de } \\
\text { desarrollo }\end{array}$}} \\
\hline & & & & & & & & & & & & & & & & \\
\hline Mexico & 5 & 48 & 41 & 27 & 43 & 28 & 40 & 40 & 44 & 50 & 69 & 65 & 206 & 43 & 7.49 & 3.94 \\
\hline Argentina & 2 & 5 & 2 & 11 & 18 & 12 & 49 & 22 & 18 & 19 & 37 & 52 & 34 & 12 & 293 & 1.54 \\
\hline Chile & 4 & 9 & 4 & 3 & 5 & 3 & 12 & 6 & 5 & 6 & 9 & 13 & 18 & 1 & 102 & 0.54 \\
\hline Otros & 7 & 304 & 111 & 64 & 101 & 65 & 275 & 124 & 102 & 133 & 209 & 286 & 178 & 70 & 2.029 & 10.68 \\
\hline Subtotal & 18 & 366 & 153 & 105 & 167 & 108 & 376 & 192 & 169 & 208 & 324 & 416 & 436 & 140 & 3.173 & 16.70 \\
\hline$\%$ & 0.56 & 11.17 & 4.31 & 3.55 & 5.83 & 3.98 & 11.26 & 6.11 & 5.20 & 6.17 & 11.16 & 13.30 & 13.23 & 4.17 & & \\
\hline Totales & 101 & 2.467 & 907 & 603 & 964 & 617 & 2.602 & 1.179 & 972 & 1.024 & 1.972 & 2.724 & 1.789 & 1.091 & 19.003 & 100.00 \\
\hline
\end{tabular}




\section{Cuadro No. 3 \\ ESTUDIANTES COLOMBIANOS EN EL EXTERIOR SEGÚN AREA DE ESTUDIO (1955 - 1968)}

\begin{tabular}{|c|c|c|c|c|c|c|c|c|c|c|c|c|c|c|c|c|}
\hline Areas de Estudio & 1955 & & & & & & & & & & & & & & & \\
\hline Aras de Estudio & 1955 & 1956 & 1957 & 1958 & 1959 & 1960 & 1961 & 1962 & 1963 & 1964 & 1965 & 1966 & 1967 & 1968 & Total & $\%$ \\
\hline Agricultura y afines & 9 & 266 & 82 & 55 & 87 & 56 & 120 & 63 & 45 & 63 & 178 & 248 & 150 & 50 & 1.472 & 7.7 \\
\hline Bellas artes & 4 & 96 & 36 & 24 & 39 & 25 & 123 & 59 & 36 & 34 & 79 & 115 & 71 & 38 & 779 & 4.1 \\
\hline $\begin{array}{l}\text { Ciencias naturales y } \\
\text { exactas }\end{array}$ & 9 & 271 & 109 & 72 & 116 & 74 & 181 & 93 & 73 & 87 & 237 & 328 & 202 & 166 & 2.018 & 10.6 \\
\hline Ciencia sociales & 11 & 280 & 154 & 103 & 164 & 105 & 389 & 257 & 207 & 211 & 335 & 432 & 303 & 201 & 3.152 & 16.6 \\
\hline Derecho & 8 & 192 & 18 & 12 & 19 & 12 & 55 & 19 & 17 & 32 & 39 & 44 & 32 & 18 & 517 & 2.7 \\
\hline Educación & 13 & 293 & 110 & 72 & 115 & 75 & 101 & 54 & 45 & 113 & 286 & 370 & 260 & 122 & 2.029 & 10.7 \\
\hline Humanidades & 9 & 215 & 64 & 42 & 67 & 43 & 261 & 140 & 155 & 134 & 94 & 180 & 83 & 93 & 1.580 & 8.3 \\
\hline Ingeniería y afines & 20 & 298 & 181 & 120 & 193 & 123 & 695 & 256 & 192 & 204 & 425 & 559 & 401 & 201 & 3.869 & 20.4 \\
\hline Ciencias medicas & 13 & 285 & 108 & 73 & 116 & 75 & 624 & 206 & 168 & 136 & 280 & 395 & 239 & 77 & 2.795 & 14.7 \\
\hline Carreras intermedias & 5 & 153 & 25 & 20 & 18 & 20 & 24 & 22 & 23 & 6 & 15 & 30 & 33 & 58 & 452 & 2.4 \\
\hline Otros & -- & 118 & 20 & 10 & 30 & 9 & 28 & 10 & 11 & 4 & 5 & 23 & 5 & 67 & 340 & 1.8 \\
\hline Total & 101 & 2.467 & 907 & 603 & 964 & 617 & 2.602 & 1.179 & 972 & 1.024 & 1.973 & 2.724 & 1.179 & 1.091 & 19.003 & $100 \%$ \\
\hline$\%$ & 0.53 & 12.91 & 4.35 & 3.16 & 5.04 & 3.23 & 13.61 & 6.17 & 5.09 & 5.36 & 10.33 & 14.26 & 9.31 & 5.71 & $100 \%$ & \\
\hline
\end{tabular}

Fuente: ICETEX

Estos períodos coinciden con los ciclos monetarios que llevan a la devaluación de 1? moneda. Así, muchos estudiantes aprovechan esta presión para comprar más divisas antes de que se decrete la evaluación.

\section{Estudiantes que regresan al país después de haber estudiado en el exterior}

El regreso de estudiantes colombianos, presenta características especiales que deben ser analizadas. Primero que todo, cada colombiano que viaje al exterior a estudiar, debe firmar un contrato con el ICETEX en donde se compromete a volver al país. Se hace esto aunque el estudiante puede sostenerse económicamente por su cuenta, ya que de todos modos disfruta de la ventaja de giros al exterior, necesaria para sus gastos. A su vez, el ICETEX administra algunos fondos fiduciarios de organizaciones privadas y públicas que desean entrenar a su personal de acuerdo a las necesidades específicas de dichas instituciones. Por recibir este beneficio, los estudiantes se comprometen a trabajar para las Instituciones patrocinadoras donde cancelan las deudas con el servicio. Generalmente se requiere que el estudiante trabaje de uno a tres años por cada año de estudio en el exterior. Como ejemplos de esta clase de contratos, se mencionan los de las Universidades para la capacitación de profesores de tiempo completo, y los de la industria petrolera para entrenar personal especializado.

La experiencia de ICETEX, enseña que tanto el contrato general en el que se compromete a la persona a volver a su país, como los acuerdos específicos de las instituciones interesadas, sirven como un catalizador para el retorno espontáneo de la gran mayoría de los profesionales colombianos.

La dificultad de mantener un registro permanente de la dirección de residencia de todos los colombianos que han estudiado en el exterior con el patrocinio del ICETEX, no ha sido obstáculo para llevar a cabo una encuesta parcial cuando regresan al país. De hecho, hay un grupo de becados que se deben reportar continuamente al instituto, después del regreso. En este grupo, están los estudiantes que obtuvieron préstamos o financiaciones del fondo fiduciario. 
De 1955 a 1968, 3.841 estudiantes viajaron al exterior, bajo alguno de los servicios mencionados anteriormente. Ello representa el 20.2\% del total de becados en el exterior por el ICETEX, durante el mismo período. Un análisis hecho por ICETEX, dio como resultado que el $97.7 \%$ de los becados, regresaron al país y actualmente están trabajando en puestos claves en los sectores públicos y privados de la economía. Únicamente el $2.3 \%$ de estos estudiantes se quedaron en el exterior.

El Cuadro No. 4, muestra el alto porcentaje de los estudiantes que regresan, comparado con la tasa sorpresivamente baja de emigración, y además la gran similitud de las tasas de retorno durante todos los años considerados.

Cuadro No. 4

EVIDENCIA DEL RETORNO DE ESTUDIANTES COLOMBIANOS EDUCADOS EN EL EXTERIOR

(1955-1968)

\begin{tabular}{|c|c|c|c|c|c|}
\hline Año & $\begin{array}{l}\text { Estudiantes } \\
\text { colombianos } \\
\text { en el } \\
\text { exterior } \\
\text { financiados } \\
\text { por el } \\
\text { ICETEX }\end{array}$ & $\begin{array}{l}\text { Miembros } \\
\text { del mismo } \\
\text { grupo que } \\
\text { regresan al } \\
\text { país }\end{array}$ & $\begin{array}{l}\text { Tasa de } \\
\text { retorno }\end{array}$ & Salida neta & $\begin{array}{l}\text { Salida } \\
\text { porcentual }\end{array}$ \\
\hline 1955 & 101 & 101 & 100.00 & --- & --- \\
\hline 1956 & 152 & 150 & 98.20 & 2 & 2.94 \\
\hline 1957 & 43 & 43 & 100.00 & --- & --- \\
\hline 1958 & 278 & 271 & 97.13 & 7 & 2.87 \\
\hline 1959 & 197 & 188 & 95.85 & 9 & 4.15 \\
\hline 1960 & 193 & 191 & 98.18 & 2 & 1.82 \\
\hline 1961 & 220 & 214 & 97.60 & 6 & 2.40 \\
\hline 1962 & 353 & 344 & 97.15 & 9 & 2.85 \\
\hline 1963 & 624 & 610 & 97.47 & 14 & 2.53 \\
\hline 1964 & 368 & 360 & 97.30 & 8 & 2.70 \\
\hline 1965 & 301 & 290 & 96.10 & 11 & 3.90 \\
\hline 1966 & 440 & 428 & 97.12 & 12 & 2.88 \\
\hline 1967 & 320 & 316 & 98.24 & 4 & 1.76 \\
\hline 1968 & 251 & 247 & 98.10 & 4 & 1.90 \\
\hline & & & & 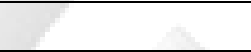 & \\
\hline Total & $\begin{array}{c}3.841 \\
\text { (20.2\% del } \\
\text { total) }\end{array}$ & 3.753 & $97.74 \%$ & 88 & $2.26 \%$ \\
\hline
\end{tabular}

Fuente: ICETEX.

Esta muestra indica que siempre hay un riesgo de emigración, dentro de los programas internacionales de educación. Sin embargo, se ha demostrado claramente que se puede controlar eficazmente.

Además, existe similitud entre los países que más atraen a los estudiantes, en términos del desarrollo académico y aquellos países en donde se quedan los emigrantes, después 
de haber terminado sus estudios. La gráfica No. 1 identifica a aquellos países que atraen o retienen a los estudiantes colombianos, con educación extranjera. El grupo de emigrantes incluidos en la muestra abarcan todas las áreas de estudio, tal como se aprecia en la Gráfica No. 2 y la profesión que representa la tasa más alta de emigración, es la ingeniería, y sus áreas relacionadas.

Es interesante anotar esto porque desde hace mucho tiempo, se ha creído que las ciencias médicas, fueron las pioneras de la emigración. Como se puede apreciar en el Cuadro No. 2, estos profesionales ocupan el tercer lugar.

\section{Análisis de la probabilidad de regreso de los colombianos que actualmente estudian en el exterior}

A partir del 31 de agosto de 1969 ICETEX patrocinaba 4.578 estudiantes en el exterior. De acuerdo al objetivo de este análisis, se dividió el grupo por países y por áreas de estudios, presentado en el Cuadro No. 5.

86.

\section{GRAFICA No. 1 \\ ATRACCION NO INTENCIONAL A PAISES \\ EXTRANJEROS}

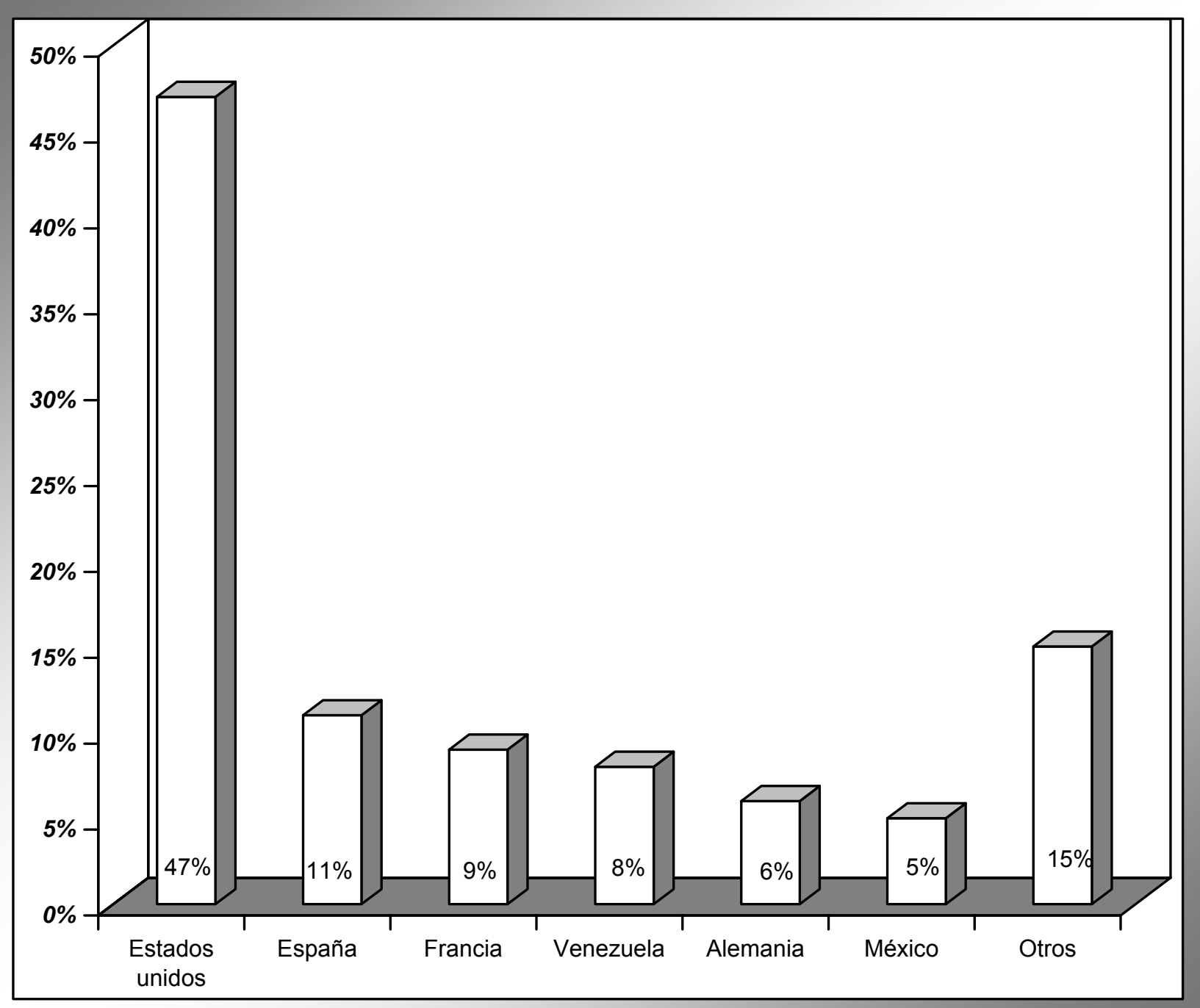




\section{GRAFICA No. 2 \\ EMIGRANTES COLOMBIANOS SEGÚN AREA DE ESTUDIO}

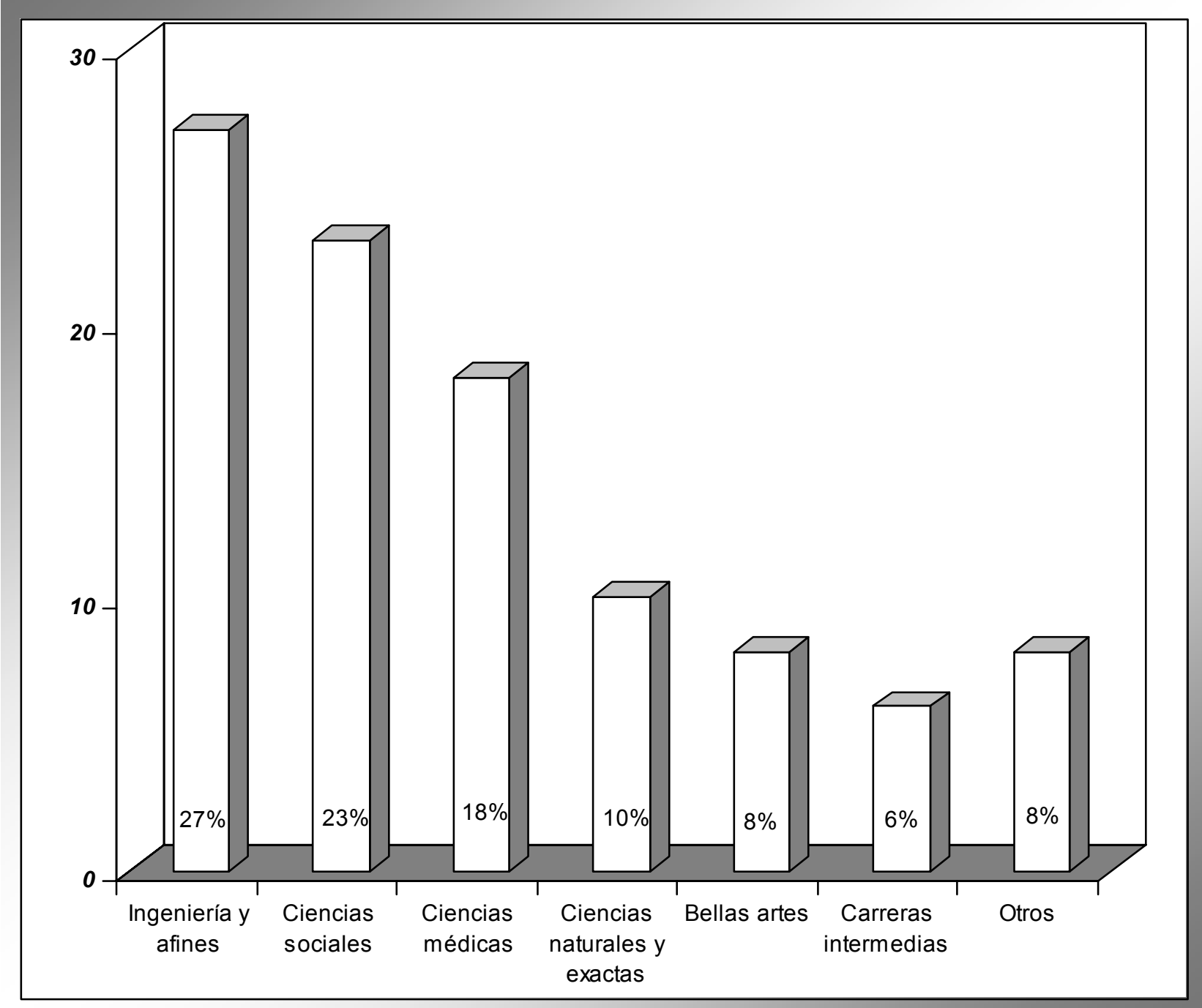

Se hizo el análisis de la probabilidad de regreso de este grupo considerando dos factores: a) El número actual de estudiantes en el exterior y b) El número de estudiantes usuarios de los préstamos de ICETEX y de los fondos fiduciarios desde diciembre de 1968.

Basados en un modelo matemático, para hallar la probabilidad de regreso de los estudiantes colombianos, y utilizando el cálculo sencillo de la probabilidad, complementado con el teorema del binomio Newton. Se consideró que el comportamiento de los eventos a través de un período de tiempo corto puede indicar la probabilidad de éxitos, o una cierta probabilidad de fracaso. La suma de estos eventos debería ser igual a uno. En la medida en que la suma de estas probabilidades se acercan a "uno", se puede decir que el procedimiento ha sido consistente.

Evidencia de regreso: Para analizar y explicar el modelo mencionado anteriormente, es necesario estudiar los cuadros que clasifican a los estudiantes que viajan al exterior, patrocinados por ICETEX. 
Tomando esto como base, se puede apreciar que la norma de regreso interrelaciona a los estudiantes que adelantan sus estudios bajo el patrocinio de ICETEX, con aquellos que regresan al país después de haber terminado sus estudios. La inter-relación se estudia en tres períodos de cinco años, a saber: 1955-1959; 1959-1963; y 1964-1968. Comparando las variaciones porcentuales que resultan de los cambios en los aspectos emigratorios e inmigratorios, se establece una relación con la media aritmética correspondiente a cada uno de los aspectos mencionados anteriormente. Se ha definido esta relación como una relación entre la evidencia emigratoria e inmigratoria, la cual ayuda a encontrar el tipo de fuerza de trabajo profesional, perdida durante el período estudiado. Se estima que los porcentajes obtenidos con este método, incluyen a los estudiantes que permanecerán en el exterior, una vez terminen los estudios.

Asumiendo que el resultado indicativo de las variables de transferencia, se deberían relacionar directamente con la unidad del sistema escogido, se puede decir que el número total de personas que abandonan sus estudios <en este caso, la perdida de estudiantes incluidos en el flujo emigratorio) será igual a la retención y/o la absorción de la entrada de la fuerza de trabajo profesional, menos la unidad total considerada. Es decir, la retención será igual a la absorción por unidad, menos los que abandonan sus estudios. De acuerdo a la anterior se concluye que:

a) La pérdida neta de talentos en el período de cinco años es equivalente al $0.21 \%$;

b) La retención, absorción o ganancia de talento, es significativa cuando se relaciona con la tasa de abandono de los estudiantes, equivalente al $99.79 \%$. 


\section{CUADRO No. 5 \\ ESTUDIANTES COLOMBIANOS EN EL EXTRANJERO 1969}

\begin{tabular}{|c|c|c|c|c|c|c|c|c|c|c|c|c|c|}
\hline Países & $\begin{array}{l}\text { Agricultura } \\
\text { y afines }\end{array}$ & $\begin{array}{c}\text { Bellas } \\
\text { artes }\end{array}$ & $\begin{array}{c}\text { Ciencias } \\
\text { naturales } \\
y \\
\text { exactas } \\
\end{array}$ & $\begin{array}{c}\text { Ciencias } \\
\text { sociales }\end{array}$ & Derecho & Educación & Humanidades & $\begin{array}{c}\text { Ingeniería } \\
\text { y afines }\end{array}$ & $\begin{array}{l}\text { Ciencias } \\
\text { medicas }\end{array}$ & $\begin{array}{c}\text { Carreras } \\
\text { intermedias }\end{array}$ & Otros & Total & $\%$ \\
\hline Estados unidos & 150 & 21 & 250 & 680 & 18 & 203 & 99 & 469 & 184 & 85 & 74 & 2.233 & 48.70 \\
\hline España & 12 & 14 & 31 & 56 & 6 & 28 & 40 & 45 & 180 & 34 & 8 & 454 & 10.00 \\
\hline Italia & 21 & 34 & 9 & 38 & 10 & 32 & 84 & 71 & 7 & 10 & 14 & 320 & 7.00 \\
\hline Alemania & 7 & 6 & 49 & 29 & 2 & 15 & 29 & 84 & 33 & 34 & 5 & 278 & 5.96 \\
\hline México & 3 & 1 & 29 & 45 & --- & 21 & 16 & 26 & 63 & 8 & 7 & 219 & 4.76 \\
\hline Francia & 4 & 7 & 19 & 72 & 9 & 11 & 24 & 19 & 28 & 5 & 9 & 207 & 4.50 \\
\hline Inglaterra & 1 & 10 & 16 & 49 & 5 & 12 & 23 & 40 & 10 & 8 & 7 & 181 & 3.95 \\
\hline Bélgica & 7 & 2 & 14 & 30 & 5 & 8 & 6 & 21 & 10 & 4 & 5 & 112 & 2.50 \\
\hline Brasil & 10 & 7 & 3 & 26 & --- & 1 & --- & 17 & 17 & --- & 1 & 32 & 1.80 \\
\hline Ecuador & 4 & 1 & 5 & 10 & --- & 11 & 7 & 4 & 24 & 9 & 1 & 76 & 1.70 \\
\hline Israel & 15 & 1 & 2 & 20 & --- & --- & 2 & 6 & 1 & --- & 4 & 51 & 1.11 \\
\hline Chile & 2 & 1 & 3 & 32 & 1 & --- & --- & 4 & --- & 1 & --- & 44 & 0.95 \\
\hline Argentina & --- & 1 & --- & 16 & 4 & 5 & 1 & 2 & 12 & 2 & --- & 43 & 0.93 \\
\hline Canadá & 3 & --- & 5 & 10 & --- & 1 & 5 & 4 & 9 & 1 & --- & 38 & 0.82 \\
\hline Austria & 2 & 3 & 1 & 6 & --- & 4 & 7 & 6 & 6 & 2 & --- & 37 & 0.80 \\
\hline & 9 & --- & 3 & 6 & --- & 3 & --- & 8 & --- & 3 & 2 & 34 & 0.74 \\
\hline Puerto Rico & 9 & --- & 4 & 5 & 2 & 2 & 2 & 5 & 5 & --- & --- & 34 & 0.74 \\
\hline Suiza & --- & 4 & 3 & 6 & 1 & 3 & 2 & 1 & 11 & --- & 1 & 32 & 0.70 \\
\hline Uruguay & 4 & --- & --- & 5 & --- & 4 & --- & 1 & 9 & --- & --- & 23 & 0.50 \\
\hline Perú & --- & 3 & 8 & 4 & --- & 1 & --- & 2 & --- & --- & 1 & 19 & 0.41 \\
\hline Honduras & 7 & --- & --- & --- & --- & 6 & --- & --- & --- & --- & 1 & 14 & 0.30 \\
\hline Costa Rica & 4 & --- & 2 & 1 & 1 & --- & --- & --- & 1 & --- & --- & 9 & 0.20 \\
\hline Noruega & --- & --- & 3 & --- & 1 & --- & --- & --- & 3 & --- & 1 & 8 & 0.17 \\
\hline Venezuela & 2 & --- & 2 & 2 & --- & --- & --- & --- & --- & --- & --- & 6 & 0.13 \\
\hline Dinamarca & --- & --- & 1 & 1 & --- & --- & --- & --- & 1 & --- & 2 & 5 & 0.10 \\
\hline Nicaragua & 5 & --- & --- & --- & --- & --- & --- & --- & --- & --- & --- & 5 & 0.10 \\
\hline Yugoeslavia & --- & --- & --- & 1 & --- & --- & --- & 3 & --- & --- & --- & 4 & 0.08 \\
\hline Japón & --- & 1 & --- & 1 & --- & --- & 1 & 1 & --- & --- & --- & 4 & 0.03 \\
\hline Filipinas & --- & --- & --- & --- & --- & 1 & 2 & --- & --- & --- & --- & 3 & 0.06 \\
\hline Panamá & --- & --- & --- & 1 & --- & --- & 1 & --- & 1 & --- & 4 & 3 & 0.05 \\
\hline Líbano & --- & --- & 1 & --- & --- & --- & --- & --- & --- & --- & --- & 1 & 0.02 \\
\hline Bolivia & --- & --- & --- & --- & --- & --- & 1 & --- & --- & --- & --- & 1 & 0.02 \\
\hline Congo & --- & --- & --- & 1 & --- & --- & --- & --- & --- & --- & --- & 1 & 0.03 \\
\hline Etiopía & --- & --- & --- & 1 & --- & --- & --- & --- & --- & --- & --- & 1 & 0.02 \\
\hline Checoslovaquia & --- & --- & --- & 1 & --- & --- & --- & --- & --- & --- & --- & 1 & 0.02 \\
\hline Total & & & & & & & & & & & & 4.576 & 100.00 \\
\hline
\end{tabular}

La Probabilidad de Regreso: En el presente análisis, se discutieron dos casos: El primero favorable a la situación que se estudia y el segundo totalmente desfavorable. El caso favorable representa la evidencia cuantificada de retorno, tomando como base los estudiantes que han vuelto al país una vez terminan el entrenamiento en el exterior. El caso desfavorable, identifica la probabilidad de que los estudiantes no vuelven al país, después de haber terminado los estudios.

Para encontrar la probabilidad de regreso de los estudiantes al país, en ambos casos (favorable y desfavorable), se debe encontrar un equilibrio que demuestre la probabilidad del regreso. El estudio referente a la probabilidad del regreso prueba que: a) La probabilidad del regreso aumentará, si las tasas de retención y la tendencia emigratoria continua siendo tan estable como están actualmente. b) Tal aumento debería ser armónico y de todos modos, representará una probabilidad de regreso más alto que uno $(P » 1)$, ya que la tendencia lógica indica que debe ser por lo menos igual a uno. Esto significaría que hay evidencia de que cada estudiante que viaje al exterior con el patrocinio del ICETEX, volverá al país por lo menos dentro de los cinco años siguientes. 


\section{B. Salida de colombianos con Intención de Emigrar}

Para los propósitos estadísticos, "un emigrante con intención" es el que sale del país por un tiempo mayor que un año con la intención de quedarse en el exterior. El Cuadro No. 6 relaciona las cifras de los colombianos emigrantes con la de los que regresan.

Cuadro No. 6

TOTAL DE EMIGRACION Y RETORNO DE ESTUDIANTES COLOMBIANOS (1955 - 1968)

\begin{tabular}{|c|c|c|c|c|}
\hline Año & Emigrantes & Retornos & Salida neta & $\%$ Neto \\
\hline 1955 & 3.996 & 1.111 & 2.885 & 4.00 \\
\hline 1956 & 4.019 & 882 & 3.137 & 4.22 \\
\hline 1957 & 4.086 & 700 & 3.386 & 4.45 \\
\hline 1958 & 5.439 & 556 & 4.883 & 5.90 \\
\hline 1959 & 7.084 & 442 & 6.642 & 8.73 \\
\hline 1960 & 8.057 & 351 & 7.706 & 10.13 \\
\hline 1961 & 7.851 & 277 & 7.574 & 10.00 \\
\hline 1962 & 9.872 & 6.194 & 3.628 & 4.80 \\
\hline 1963 & 12.654 & 6.181 & 6.473 & 8.55 \\
\hline 1964 & 11.028 & 1.140 & 9.888 & 13.00 \\
\hline 1965 & 11.167 & 939 & 10.228 & 13.50 \\
\hline 1966 & 7.745 & 1.669 & 6.076 & 8.00 \\
\hline 1967 & 3.049 & 1.180 & 1.869 & 2.50 \\
\hline 1968 & 3.360 & 1.676 & 1.684 & 2.22 \\
\hline
\end{tabular}

Fuente: $\quad$ Anuario Estadístico DANE.

Nota: Los retornos de 1955 a 1961 son estimados debido a deficiencias estadísticas. Para dicha estimación se compararon los períodos anormales, obteniendo una media geométrica, equivalente al $20 \%$.

\section{Indicadores de "Intención Permanente"}

A través del período estudiado, 99.357, colombianos a todo nivel, salieron del país para quedarse en el exterior, por un período mayor de un año, de los cuales, 23.298 regresaron. La emigración total, sumó 76.059 personas. De 1955 a 1965, hubo un aumento continuo en la emigración neta de los colombianos, acentuada especialmente entre los años 1964 y 1965, cuando las salidas se triplicaron en relación a los once años anteriores. Por el contrario, en 1967 y 1968, disminuyó la tasa de emigrantes considerablemente coincidiendo con la estabilidad económica del país y con la generación de un mayor nivel de empleo. Las tasas de emigración durante los últimos dos años, son las más bajas del período. 


\section{Categorías incluidas en el análisis anterior}

El Cuadro No. 7, indica que las 38.398 personas que emigraron de Colombia durante el período estudiado, pertenecían a la categoría de profesionales de alto nivel.

El mayor porcentaje de emigrantes, pertenece a las áreas de ingeniería, administración, educación, ciencias médicas y las artes. Entre 1960 y 1963, la salida de profesionales de este nivel representó aproximadamente el $40 \%$. El Cuadro No. 8, muestra que 16.928 profesionales regresaron al país dejando un saldo neto de 21.470 emigrantes del mismo nivel. Los campos de estudio que, por lo general, representan un regreso mayor, corresponden a aquellos con la tasa de deserción más alta, a excepción de la educación y las ciencias sociales.

El Cuadro No. 9, muestra que 11.302 colombianos de nivel intermedio salieron del país, principalmente en las áreas de Tecnología Industrial y Mecánica, contadores y oficinistas. Aunque la mayoría de estas personas no ha tenido educación universitaria, representan un grupo importante que ha adquirido sus conocimientos a través de la experiencia.

De este grupo de nivel intermedio, 4.482 personas, regresaron al país, dejando el saldo neto en 6.820 para esta categoría, que aparece discriminada por áreas en el Cuadro No. 10.

Resumiendo: el problema migratorio colombiano, de acuerdo con los datos que se tienen se pueden describir de la siguiente manera:

Salidas totales entre 1955 y 1968 :

Menos número total de personas que regresaron:

19.554

Emigración neta:

79.803

Esta cifra incluye: a) 21.470 personas de alto nivel, o el $27 \%$ del total; b) 6.820 personas de nivel intermedio, o el $9 \%$ del total; y e) 51.513 personas de otras categorías, incluyendo a niños, o el $64 \%$ del total.

\section{CUADRO No. 7 \\ SALIDA DE PROFESIONALES COLOMBIANOS DE ALTO NIVEL (1955-1968)}

\begin{tabular}{|c|c|c|c|c|c|c|c|c|c|c|c|c|c|c|c|c|}
\hline Áreas de estudio & 1955 & 1956 & 1957 & 1958 & 1959 & 1960 & 1961 & 1962 & 1963 & 1964 & 1965 & 1966 & 1967 & 1968 & Total & $\%$ \\
\hline $\begin{array}{c}\text { Agricultura y } \\
\text { afines }\end{array}$ & 42 & 27 & 17 & 22 & 51 & 96 & 94 & 106 & 130 & 49 & 55 & 62 & 36 & 40 & 827 & 2.15 \\
\hline Bellas artes & 459 & 178 & 146 & 111 & 340 & 456 & 444 & 296 & 275 & 91 & 56 & 259 & 21 & 23 & 3.155 & 8.22 \\
\hline $\begin{array}{c}\text { Ciencias } \\
\text { Naturales y } \\
\text { exactas }\end{array}$ & 200 & 153 & 103 & 185 & 192 & 178 & 173 & 166 & 121 & 76 & 108 & 150 & 50 & 55 & 1.910 & 4.97 \\
\hline Ciencias sociales & 61 & 41 & 32 & 34 & 59 & --- & --- & --- & --- & 65 & 154 & 63 & 510 & 562 & 1.581 & 4.12 \\
\hline $\begin{array}{c}\text { Administración y } \\
\text { economía }\end{array}$ & 1.049 & 507 & 218 & 282 & --- & 1.158 & 1.137 & 1.223 & 742 & 136 & 248 & 670 & 103 & 114 & 7.587 & 19.70 \\
\hline Derecho & 183 & 166 & 42 & 68 & 113 & 226 & 220 & 169 & 115 & 62 & 96 & 132 & 25 & 28 & 1.645 & 4.28 \\
\hline Educación & 417 & 240 & 197 & 126 & 313 & 515 & 501 & 511 & 499 & 243 & 241 & 345 & 297 & 327 & 4.772 & 12.43 \\
\hline Ingeniería y afines & 1.722 & 950 & 672 & 672 & 847 & 1.234 & 1.211 & 1.102 & 734 & 314 & 495 & 905 & 204 & 2257 & 11.196 & 29.42 \\
\hline Ciencias medicas & 342 & 200 & 141 & 221 & 319 & 354 & 345 & 462 & 455 & 271 & 259 & 306 & 63 & 69 & 3.807 & 9.91 \\
\hline Otros & 199 & 475 & 216 & 218 & 304 & --- & --- & --- & --- & 70 & 98 & 225 & 6 & 7 & 1.818 & 4.74 \\
\hline Total & 4.674 & 2.937 & 1.784 & 1.939 & 2.538 & 4.226 & 4.125 & 4.035 & 3.071 & 1.377 & 1.810 & 3.117 & 1.315 & 1.450 & 38.398 & $100 \%$ \\
\hline
\end{tabular}

Fuente: DANE 


\section{CUADRO No. 8 \\ RETORNO DE COLOMBIANOS DE ALTO NIVEL (1955 - 1968)}

\begin{tabular}{|c|c|c|c|c|c|c|c|c|c|c|c|c|c|c|c|c|}
\hline Áreas de estudio & 1955 & 1956 & 1957 & 1958 & 1959 & 1960 & 1961 & 1962 & 1963 & 1964 & 1965 & 1966 & 1967 & 1968 & Total & $\%$ \\
\hline Agricultura y afines & 14 & 15 & 12 & 15 & 6 & 33 & 32 & 49 & 70 & 21 & 30 & 27 & 41 & 58 & 423 & 2.50 \\
\hline Bellas artes & 33 & 61 & 47 & 75 & 36 & 149 & 144 & 130 & 108 & 22 & 18 & 74 & 19 & 27 & 943 & 5.55 \\
\hline $\begin{array}{c}\text { Ciencias Naturales y } \\
\text { exactas }\end{array}$ & 30 & 31 & 54 & 71 & 34 & 84 & 82 & 86 & 102 & 71 & 48 & 63 & 50 & 71 & 877 & 5.18 \\
\hline Ciencias sociales & 18 & 15 & 11 & 6 & 4 & --- & --- & --- & --- & 401 & 128 & 63 & 511 & 726 & 1.903 & 11.24 \\
\hline $\begin{array}{c}\text { Administración y } \\
\text { economía }\end{array}$ & 96 & 100 & 94 & 86 & 115 & 325 & 315 & 428 & 382 & 183 & 129 & 204 & 111 & 158 & 2.726 & 16.11 \\
\hline Derecho & 95 & 93 & 77 & 14 & 22 & 36 & 25 & 78 & 57 & 22 & 19 & 48 & 25 & 36 & 637 & 3.76 \\
\hline Educación & 92 & 81 & 66 & 116 & 49 & 202 & 196 & 295 & 367 & 330 & 280 & 188 & 281 & 399 & 2.942 & 17.38 \\
\hline Ingeniería y afines & 395 & 363 & 311 & 246 & 94 & 414 & 402 & 497 & 476 & 291 & 203 & 336 & 205 & 291 & 4.521 & 28.25 \\
\hline Ciencias medicas & 123 & 134 & 115 & 37 & 7 & 35 & 34 & 215 & 259 & 65 & 43 & 97 & 63 & 89 & 1.316 & 7.77 \\
\hline Otros & 51 & 186 & --- & 26 & --- & --- & --- & --- & --- & 77 & 86 & 85 & --- & 121 & 632 & 3.74 \\
\hline Total & 947 & 1.079 & 787 & 692 & 357 & 1.278 & 1.230 & 1.778 & 1.821 & 1.483 & 989 & 1.205 & 1.306 & 1.976 & 16.928 & $100 \%$ \\
\hline
\end{tabular}

Fuente: DANE

CUADRO No. 9

SALIDA DE PERSONAL COLOMBIANO DE NIVEL INTERMEDIO (1955 - 1968)

\begin{tabular}{|c|c|c|c|c|c|c|c|c|c|c|c|c|c|c|c|c|}
\hline $\begin{array}{ll}\text { Área } & \text { de } \\
\text { estudio } & \end{array}$ & 1955 & 1956 & 1957 & 1958 & 1959 & 1960 & 1961 & 1962 & 1963 & 1964 & 1965 & 1966 & 1967 & 1968 & Total & $\%$ \\
\hline Diseñadores & 27 & 24 & 21 & 23 & --- & 24 & 4 & 91 & 78 & 34 & 57 & 38 & 10 & 11 & 447 & 3.26 \\
\hline Enfermeras & 74 & 54 & 63 & 37 & 85 & 72 & 70 & 68 & 103 & 67 & 47 & 67 & 18 & 20 & 845 & 7.48 \\
\hline $\begin{array}{l}\text { Asistentes } \\
\text { médicos }\end{array}$ & 28 & 13 & 21 & 19 & 6 & 40 & 40 & 32 & 53 & 44 & 47 & 31 & 70 & 77 & 526 & 4.65 \\
\hline $\begin{array}{l}\text { Contadores } \\
\text { y oficinistas }\end{array}$ & 232 & 157 & 126 & 122 & 221 & 12 & 11 & 33 & 239 & 144 & 153 & 131 & 127 & 140 & 1.848 & 16.35 \\
\hline Interpretes & 172 & 95 & 75 & 62 & 25 & --- & --- & --- & --- & 49 & 56 & 76 & 26 & 29 & 665 & 5.88 \\
\hline Telefonistas & 69 & 48 & 29 & 32 & 17 & 14 & 13 & 33 & 18 & 11 & 6 & 26 & 2 & 2 & 320 & 2.83 \\
\hline $\begin{array}{l}\text { Técnicas en } \\
\text { mecánica }\end{array}$ & 330 & 203 & 156 & 228 & 272 & 10 & 231 & 365 & 42 & 287 & 248 & 215 & 33 & 36 & 2.656 & 23.50 \\
\hline $\begin{array}{l}\text { Técnicas } \\
\text { electrónicas }\end{array}$ & 100 & 52 & 28 & 29 & 60 & 38 & 38 & 55 & 104 & 54 & 65 & 48 & 7 & 8 & 636 & 6.07 \\
\hline Fotógrafos & 24 & 21 & 9 & --- & 24 & 19 & 6 & --- & 30 & 17 & 2 & 15 & 3 & 3 & 173 & 1.53 \\
\hline $\begin{array}{l}\text { Técnicos } \\
\text { industriales }\end{array}$ & 228 & 142 & 140 & 155 & 186 & 505 & 492 & 509 & 214 & --- & 11 & 258 & --- & 284 & 3.124 & 27.64 \\
\hline $\begin{array}{l}\text { Asistentes } \\
\text { sociales }\end{array}$ & --- & --- & --- & --- & --- & --- & --- & --- & --- & 5 & 7 & --- & --- & --- & 12 & 0.11 \\
\hline & & & & & & & & & & & & & & & & \\
\hline Subtotal & 1.284 & 809 & 663 & 712 & 896 & 734 & 905 & 1.186 & 886 & 712 & 699 & 905 & 296 & 610 & 11.302 & $100 \%$ \\
\hline Otros & 14.250 & 9.964 & 7.662 & 9.850 & 12.668 & 14.367 & 13.803 & 16.291 & 17.763 & 11.900 & 12.457 & 12.822 & 2.306 & 3.037 & 89.754 & $100 \%$ \\
\hline & & & & & & & & & & & & & & & & \\
\hline salida & 20.203 & 13.710 & 10.114 & 2.501 & 16.102 & 19.327 & 18.833 & 21.515 & 21.725 & 14.000 & 14.969 & 16.844 & 4.403 & 5.147 & 209154 & \\
\hline
\end{tabular}

\section{CUADRO No. 10}

RETORNO DE COLOMBIANOS DE NIVEL INTERMEDIO

(1956 - 1968)

\begin{tabular}{|c|c|c|c|c|c|c|c|c|c|c|c|c|c|c|c|}
\hline Área de estudio & 1956 & 1957 & 1958 & 1959 & 1960 & 1961 & 1962 & 1963 & 1964 & 1965 & 1966 & 1967 & 1968 & Total & $\%$ \\
\hline Diseñadores & 7 & 11 & 13 & --- & --- & --- & 20 & 28 & 2 & 11 & 12 & 9 & 13 & 133 & 2.07 \\
\hline Enfermeras & 22 & 20 & 14 & 6 & 33 & 32 & 37 & 42 & 22 & 10 & 23 & 18 & 25 & 326 & 7.07 \\
\hline Asistentes médicos & --- & 8 & 13 & --- & 14 & 13 & 25 & --- & 23 & 9 & 14 & 70 & 99 & 297 & 6.03 \\
\hline Contadores y oficinistas & 51 & 48 & 48 & 25 & 6 & 7 & 160 & 109 & 88 & 36 & 57 & 104 & 148 & 940 & 20.97 \\
\hline Interpretes & 46 & 10 & 31 & 8 & --- & --- & $\begin{array}{ll}-- \\
\end{array}$ & $\begin{array}{ll}--- \\
\end{array}$ & 17 & 18 & 23 & 16 & 23 & 226 & 5.04 \\
\hline Telefonistas & --- & --- & --- & 1 & 4 & 4 & 9 & 5 & 1 & --- & 4 & 2 & 3 & 33 & 0.74 \\
\hline Técnicas en mecánica & 86 & 66 & 84 & 47 & 171 & 145 & 32 & 17 & 42 & --- & 78 & 23 & 47 & 946 & 21.11 \\
\hline Técnicas electrónicas & 39 & 19 & 27 & 9 & --- & 22 & 33 & 30 & 20 & 11 & 24 & 7 & 10 & 285 & 6.36 \\
\hline Fotógrafos & --- & 4 & --- & 6 & 14 & 13 & 11 & 14 & 5 & 9 & --- & 3 & 4 & 83 & 1.85 \\
\hline Técnicos industriales & 66 & 77 & 86 & 42 & 215 & 208 & 154 & 215 & 13 & --- & 119 & 3 & 4 & 1.202 & 26.82 \\
\hline Asistentes sociales & --- & --- & --- & --- & --- & --- & --- & --- & 7 & 4 & --- & --- & --- & 11 & 0.24 \\
\hline Total & 17 & 263 & 314 & 144 & 457 & 444 & 481 & 460 & 240 & 108 & 354 & 265 & 376 & 4.482 & $100 \%$ \\
\hline
\end{tabular}




\section{Evidencia de Regreso entre Emigrantes a pesar de la intención de Emigración Permanente}

Los cuadros No, 9 y 10, indican el número de estudiantes que regresaron, ubicados a niveles altos e intermedios, durante el período del estudio. En relación con la primera categoría, se puede observar que los principales grupos de profesionales que regresan al país, son los siguientes: Ingenieros, 26.7\%; seguidos por profesores, 17.4\%; administradores, 16.1\%; y científicos sociales, $11.3 \%$. En la categoría intermedia, el principal número de personas que regresaron fueron los técnicos industriales y mecánicos.

\section{Empleo de Extranjeros en Colombia}

Colombia no ha tenido una política abierta y definida en relación con la inmigración.

El censo demográfico de 1964, indicó que únicamente había 74.053 extranjeros en el país, representando el $0.4 \%$ de la población total. Según el mismo censo, de los 74.053 extranjeros, 33.129 son activos económicamente, de los cuales, según el registro nacional, de extranjeros, 4.728 eran profesionales.

El mayor porcentaje de profesionales extranjeros, corresponde a los Estados Unidos, con el $28.7 \%$ del total, los europeos siguen con el $38.4 \%$ siendo la gran mayoría españoles, los latinoamericanos, constituyen el $24 \%$ del total.

En relación con áreas de especialización, la concentración más alta de extranjeros, se encuentra en el campo de las ciencias sociales, 23.5\%; seguido por educación, $24.4 \%$; e ingeniería, $23.5 \%$. El flujo de la fuerza de trabajo profesional extranjera, representa el 23 $\%$ del total de la fuerza de trabajo profesional colombiana que emigra.

\section{Destino de la Salida de la Mano de Obra Profesional}

Teniendo en cuenta que el Departamento Nacional de Estadística (DANE), no tiene ninguna información sobre el país de destino de los emigrantes colombianos, hay que seguir dos métodos para averiguar esta información. El primero está relacionado con los países a donde van los estudiantes después de terminar sus programas de entrenamiento, que según se mencionó anteriormente, son los siguientes:

Estados Unidos, 46.5\%; España, 10.8\%; Francia, 7.8\%; Venezuela, 7.8\%; México, $4.5 \%$ y Canadá, $3.4 \%$. Estos países pueden llamarse "polos de desarrollo", con relación a Colombia.

El segundo método consiste en el análisis de los datos sobre la salida de los emigrantes a los Estados Unidos, ya que este país atrae a la gran mayoría de emigrantes. 
Cuadro No. 11

\section{EMIGRACION DE PROFESIONALES COLOMBIANOS A ESTADOS UNIDOS DE AMERICA \\ (1961-1968)}

\begin{tabular}{|c|c|c|c|c|c|c|c|c|c|c|}
\hline & $\mathbf{1 9 6 1}$ & $\mathbf{1 9 6 2}$ & $\mathbf{1 9 6 3}$ & $\mathbf{1 9 6 4}$ & $\mathbf{1 9 6 5}$ & $\mathbf{1 9 6 6}$ & $\mathbf{1 9 6 7}$ & $\mathbf{1 9 6 8}$ & Total & $\mathbf{\%}$ \\
\hline Áreas de estudio & & & & & & & & & & \\
\hline Agricultura y afines & 1 & --- & 5 & 4 & 4 & 5 & --- & 1 & 20 & 0.60 \\
\hline Bellas artes & 18 & 21 & 24 & 48 & 17 & 39 & 2 & 28 & 197 & 5.30 \\
\hline Ciencias sociales & 6 & 9 & 15 & 23 & 18 & 21 & 10 & 12 & 114 & 3.00 \\
\hline $\begin{array}{c}\text { Ciencias Naturales y } \\
\text { exactas }\end{array}$ & 12 & 11 & 19 & 26 & 18 & 27 & 8 & 23 & 144 & 3.70 \\
\hline Derecho & 7 & 8 & 11 & 16 & 18 & 6 & --- & 10 & 76 & 2.05 \\
\hline Educación & 53 & 76 & 98 & 136 & 111 & 103 & 44 & 69 & 690 & 17.30 \\
\hline Ingeniería y afines & 37 & 56 & 74 & 110 & 42 & 149 & 78 & 156 & 702 & 13.40 \\
\hline Ejecutivos & 43 & 74 & 100 & 126 & --- & 77 & 16 & 82 & 518 & 13.35 \\
\hline Ciencias medicas & 87 & 135 & 176 & 273 & 173 & 160 & 163 & 252 & 1.419 & 36.30 \\
\hline & & & & & & & & & & \\
\hline Total & $\mathbf{2 6 4}$ & $\mathbf{3 9 0}$ & $\mathbf{5 2 2}$ & $\mathbf{7 6 2}$ & $\mathbf{4 0 1}$ & $\mathbf{5 8 7}$ & $\mathbf{3 2 1}$ & $\mathbf{6 3 3}$ & $\mathbf{3 . 8 8 0}$ & $\mathbf{1 0 0 \%}$ \\
\hline $\mathbf{6}$ & $\mathbf{6 . 3 1}$ & $\mathbf{1 0 . 2 0}$ & $\mathbf{1 3 . 1 7}$ & $\mathbf{1 9 . 2 4}$ & $\mathbf{1 0 . 2 6}$ & $\mathbf{1 6 . 0 0}$ & $\mathbf{8 . 6 0}$ & $\mathbf{1 6 . 2 2}$ & & \\
\hline
\end{tabular}

Fuente: Estados Unidos Departamento de Justicia, Servicio de Inmigración y naturalización.

Nota: Durante el mismo período 17.760 colombianos de diferentes categorías educativas emigraron a los Estados Unidos.

Entre 1961 y 1968, 3.880 profesionales colombianos, emigraron a los Estados Unidos, como lo indica el Cuadro No. lila mayor fuga corresponde a los médicos y profesiones relacionados, como las enfermeras y del sector paramédico en general. Los ingenieros ocupan el segundo lugar de los emigrantes, seguidos por los educadores y científicos sociales, de los cuales los ejecutivos administradores representa el $13.35 \%$.

El caso que ha creado más preocupación, es el de la emigración de médicos. La Asociación Americana de Medicina, por ejemplo, registra a los médicos extranjeros activos en los Estados Unidos, y Colombia ocupa el cuarto puesto de los exportadores de médicos a los Estados Unidos y el undécimo en el mundo. Mientras que las Filipinas tiene el $26 \%$ de sus médicos graduados en los Estados Unidos, Colombia tiene el $3 \%$. La razón principal para esta fuga continua es la disponibilidad de puestos para internos en el mencionado país.

Entre 1965 y 1966 por ejemplo, el 19\% de los puestos para internos, fueron médicos extranjeros, el $56 \%$ médicos norte-americanos y el $25 \%$ restante quedo vacante ${ }^{19}$.

Actualmente hay dificultades serias en las relaciones laborales entre los hospitales universitarios colombianos y los médicos internos y residentes debido a los sueldos e incentivos, comparativamente bajos con respecto a la estructura salarial del país. Sin embargo, el gobierno subsidiará este servicio con el fin de que el entrenamiento profesional pueda competir con la educación de post-grado en el extranjero.

\footnotetext{
${ }^{19}$ Harold Margulis, Lucille stephenson Bloch, "Foreing Medical Graduates in the United States”. Harvard University Press, 1969. 


\section{Tendencias y factores que producen a emigración de la fuerza de trabajo profesional de Colombia}

Se deben analizar completamente las estadísticas en el capítulo anterior tanto para observar el fenómeno migratorio durante el período que abarca este estudio como para investigar los factores que los motivan y recomendar algunas medidas correctivas, si es el caso.

\section{A. Análisis de las principales tendencias observadas en las estadísticas anteriores}

\section{Tendencias de disminución y aumento en la emigración general de la fuerza de trabajo de los niveles altos e intermedios desde 1955.}

Evaluación y análisis general de las profesiones más significativas: El Cuadro No. 7 , Capítulo I muestra una tendencia descendente en la emigración profesional colombiana a países extranjeros, tal como lo indican las cifras del Departamento Nacional de Estadísticas, DANE. Aunque hubo un gran aumento en el flujo emigratorio en el período de 1960 a 1963, esta cifra nunca alcanzó el elevado número de emigrantes registrados en 1955. Esta tendencia hacia una disminución cuantitativa del problema, esta estrechamente relacionado con la intención de los emigrantes. En los últimos dos años, también hubo una disminución en el flujo migratorio a nivel intermedio.

Para lograr un enfoque más objetivo de la disminución de las tendencias, se recomienda hacer un estudio gráfico de la migración en los niveles altos e intermedios, hacía los países más desarrollados, ya que hay diferencia en el comportamiento de las diversas profesiones, según las áreas de estudio.

El mayor número de emigrantes corresponde al campo de la ingeniería y otras profesiones relacionadas con esta, aunque al observar el caso concreto de los emigrantes a los Estados Unidos, la mayor cifra corresponde a las profesiones médicas y paramédicas. En la Gráfica No. 3, se presentan tres ciclos, y los períodos correspondientes al aumentó y disminución. El primer ciclo, se refiere a los años 1955 a 1957; el segundo, a los años 1958 a 1964; y el tercero, a los años 1964 y 1967. Se puede observar que hay una disminución progresiva del número de ingenieros emigrantes y otras profesiones relacionadas con esta; llegando a 204 personas en 1967, la cifra más baja del período. En 1968 hubo un ligero aumento en el nivel de migración, no lo suficientemente significativo como para considerar que podría modificar la tendencia.

Al proyectar esta tendencia a 1975, teniendo en cuenta la tendencia decreciente, se puede colegir que la cifra de emigración para los ingenieros, se estabilizará por debajo de la cifra más baja registrada en dicho período. Es decir, la emigración de los ingenieros no constituye un problema cuantitativo serio para el futuro, especialmente si se considera que la demanda para esta profesión en el país ha aumentado en forma satisfactoria y que los sueldos son comparativamente más altos que los de otras profesiones. Sin embargo, desde el punto de vista cualitativo, el problema de emigración de los ingenieros colombianos es importante, si se considera que la comunidad internacional, únicamente íntegra a los ingenieros altamente calificados con un nivel de formación por encima del promedio.

La emigración profesional en las áreas de administración, educación, ciencias médicas y afines y el derecho, se nota que los tres primeros corresponden a la cifra más alta de la 
emigración profesional, después de la ingeniería. Se incluyó al derecho para observar el fenómeno, puesto que en esta carrera se encuentra el mayor número de profesionales.

En relación con la administración, se debe enfatizar el hecho de que apenas se inició la enseñanza de esta ciencia en Colombia en 1961, y por lo tanto, aquellos que aparecen como emigrantes, no necesariamente recibieron la formación, dentro del sistema universitario. Se puede asumir que ellos mismos se llaman administradores" porque lograron ocupar puestos por su experiencia o por la movilidad propia de este campo. En el estudio de recursos humanos del ICETEX, se encontró que el $76 \%$ de los administradores del país, no tenían educación universitaria y el resto tenían otras profesiones.

La tendencia de la emigración de estos profesionales, también está disminuyendo y se supone que en el futuro, este nivel de emigración, será más bajo que en otras profesiones. Se llegó a esta conclusión, al considerar que la notable disminución de la emigración de estos profesionales en los últimos años, puede deberse al hecho de que el termino administrador" se refiera a aquellos que realmente han estudiado esta carrera universitaria. Como es el caso de la emigración de los ingenieros, se puede clasificar este hecho en tres ciclos que corresponden a los mismos períodos analizados, con la diferencia que en el ciclo intermedio, (1958-1964), se encuentran las cifras más elevadas de emigración profesional. El último ciclo muestra las cifras más bajas de los tres, lo cual determina la tendencia negativa dentro de ese período.

Con respeto a la educación, la tendencia emigrante está disminuyendo. Al proyectar dicha tendencia a 1975, resultará ser la más baja del período estudiado; es decir, inferior a 241. La emigración profesional que corresponde a este campo de conocimiento, también se divide en tres ciclos, pero el período de tiempo tomado, varía en la siguiente forma: el primer ciclo, de 1955 a 1958; el segundo de 1958-1965 y el tercero de 1965 a 1967. El ciclo intermedio registra la mayor emigración profesional y el último ciclo, la menor, lo que confirma la disminución de la tendencia dentro de la profesión.

Se considera que la educación es la profesión más estable de todas las analizadas. Se explica este hecho por la demanda internacional en los campos de la enseñanza y de la investigación científica. Las universidades norte-americanas, por ejemplo, dan a los profesores extranjeros la oportunidad de estudiar y practicar simultáneamente, otorgándoles becas de investigación con la modalidad de profesor visitante. Las Universidades europeas también ofrecen un plan similar. En estos casos, la emigración produce efectos favorables por ser una posible fuente de transferencia de conocimientos, asumiendo que la persona regrese a su país de origen.

En el caso de la emigración en el campo de las ciencias médicas, se puede notar que este fenómeno es nuevo y empezó a aumentar considerablemente entre 1957 y 1962 y a disminuir en 1963; indicando así, la tendencia en este campo. Sin embargo, es un hecho que la emigración de profesionales hacia los Estados Unidos, se debe en parte a un déficit apreciable de estos profesionales y en parte al número de cupos vacantes para los residentes en hospitales. Según las estadísticas de inmigración de Estados Unidos, los médicos constituyeron el mayor grupo entre los profesionales colombianos alcanzando el $36.3 \%$ del total de emigrantes colombianos a ese país. Según estos datos, la tendencia es positiva, y el mayor número de emigrantes fueron en los años 1964-1968. Se debe anotar que la mayoría de los profesionales médicos que trabajan como internos y residentes en los hospitales de los estados Unidos y Canadá, sí regresan al país. La Asociación Colombiana de Escuelas de Medicina lleva y mantiene un registro de la práctica de especializaciones en medicina, indicando que hay una tendencia importante a regresar. 
En relación con el campo del derecho, la misma cifra muestra una tendencia baja de emigración, probablemente debido al hecho de que la enseñanza de esta profesión se relaciona directamente con la ley nacional, y la imposibilidad de practicarlo en el exterior. El mayor número de emigrados de este período corresponde a 1960, año en el cual emigraron 226 abogados. Esta tendencia emigratoria es relativamente estable.

La tendencia en relación con la emigración en las áreas de las ciencias exactas y naturales, bellas artes, agricultura, profesiones afines, y en las ciencias sociales es negativa para las tres primeras, y positiva en la última. En los últimos dos años, el mayor número de emigrantes profesionales colombianos correspondió al campo de las ciencias sociales.

\section{La tendencia emigratoria en proporción a los niveles altos e intermedios}

El Cuadro No. 12 muestra el recurso humano profesional colombiano de alto nivel en 1969, lo cual representa la oferta potencial para el mercado de trabajo. El cuadro está basado en los datos del censo de 1964 adicionando para cada año siguiente los graduandos en educación superior.

Partiendo de esa información se hizo un estudio sobre la relación entre la capacidad de trabajo profesional por área y por el número de emigrantes. El inventario de la fuerza de trabajo profesional debe ser reducido en $6.3 \%$ equivalente a la tasa de mortalidad,

\begin{tabular}{|l|c|c|c|c|c|c|c|c|c|}
\hline \multicolumn{7}{|c|}{ Inventario de nuevos graduados } \\
\hline \multicolumn{1}{|c|}{ Áreas de estudio } & Inventario de personal censo de 1964 & $\mathbf{1 9 6 4}$ & $\mathbf{1 9 6 5}$ & $\mathbf{1 9 6 6}$ & $\mathbf{1 9 6 7}$ & $\mathbf{1 9 6 8}$ & $\mathbf{1 9 6 9}$ & Emigración neta & \%- \\
\hline Agricultura y afines & 2.271 & 271 & 404 & 460 & 470 & 479 & 4.355 & 404 & 9.27 \\
\hline Bellas artes & 2.214 & 15 & 202 & 171 & 258 & 176 & 3.036 & 2.212 & 72.86 \\
\hline Ciencias naturales y exactas & 1.875 & 428 & 141 & 151 & 119 & 174 & 2.888 & 1.033 & 35.77 \\
\hline Ciencias sociales & 263 & 488 & 1.010 & 1.038 & 316 & 1.016 & 4.131 & --- & 0.0 \\
\hline Derecho & 11.199 & 793 & 752 & 716 & 784 & 344 & 14.588 & 1.008 & 6.91 \\
\hline Educación & 444 & 426 & 509 & 714 & 667 & 988 & 3.748 & 1.830 & 48.83 \\
\hline Humanidades & --- & 160 & 345 & 168 & 280 & 872 & 1.825 & -- & 0.0 \\
\hline Ingeniería y afines & 8042 & 1.028 & 1.038 & 1.141 & 1.245 & 1.357 & 13.851 & 6.667 & 48.13 \\
\hline Ciencias médicas & 18.197 & 699 & 906 & 1.045 & 368 & 897 & 22.112 & 2.491 & 11.26 \\
\hline Administración y economía & 7.565 & 584 & 634 & 691 & 748 & 740 & 10.962 & 4.861 & 44.34 \\
\hline & & & & & & & & & \\
\hline Total & $\mathbf{5 2 . 0 7 0}$ & $\mathbf{4 . 8 9 2}$ & $\mathbf{5 . 9 4 1}$ & $\mathbf{6 . 2 9 5}$ & $\mathbf{5 . 2 5 5}$ & $\mathbf{7 . 0 4 3}$ & $\mathbf{8 1 . 4 9 6}$ & $\mathbf{2 1 . 6 9 2}$ & $\mathbf{2 7 . 7 3}$ \\
\hline
\end{tabular}

Fuente: DANE - ICFES.

conclusión hecha en una investigación realizada en ICETEX en 1964 sobre "La capacidad de trabajo"

El comportamiento de las tendencias migratorias dentro de cada grupo profesional, con respecto al inventario disponible de los recursos humanos, muestra en general una disminución de la fuerza de trabajo profesional de alto nivel en un $27.7 \%$ debido al factor emigratorio. Los problemas más serios se encuentran en las áreas de las artes, la educación, la ingeniería, profesiones afines, y en la administración.

Esta cifra representa la mayor concentración de los recursos humanos como también la mayor o menor pérdida en cada una de las áreas. Las profesiones menos afectadas son la agricultura y profesiones afines, ciencias sociales, humanidades, derecho y medicina. 


\section{Tendencias según las edades de los Emigrantes}

La Gráfica No. 3 muestra que hay una tendencia creciente de emigrar entre los 20 y 49 años. Hay distintos períodos que revelan esta tendencia creciente y son los comprendidos entre 1956 a 1961, 1962 a 1964, y 1965 a 1968.

El primero tiene un total de 49.742 emigrantes; el segundo 34.912; el tercero 45.701. Entre ellos, la tendencia más consistente fue la última que todavía continúa su ritmo ascendente. El hecho de que el número de emigrantes del último período se acerque más a la cifra del primer período, demuestra la creciente tendencia dominante.

Tendencias según el nivel de entrenamiento: La emigración del personal de alto nivel es tres veces mayor que la del nivel intermedio, cuando debería ser lo contrario teniendo en cuenta que cada profesional requiere de 3 a 5 técnicos para trabajar con él, según los cálculos hechos por los analistas del trabajo.

La mayoría de los técnicos son personas que han adquirido sus conocimientos por medio de la experiencia. En Colombia este nivel formal de educación apenas se encuentra en su etapa inicial.

\section{Tendencias en la importación de personas altamente capacitadas}

El mayor número de profesionales extranjeros en Colombia, el $67.7 \%$, llegan de los países más desarrollados, y entre ellos, el mayor porcentaje corresponde a los europeos. Los Estados Unidos ocupa el primer lugar con un porcentaje del $28.7 \%$.

Las ciencias sociales ocupan el primer lugar en términos de las áreas de estudio, con los administradores y el personal de nivel ejecutivo. El segundo lugar corresponde a los educadores, y el tercero, a los ingenieros. 


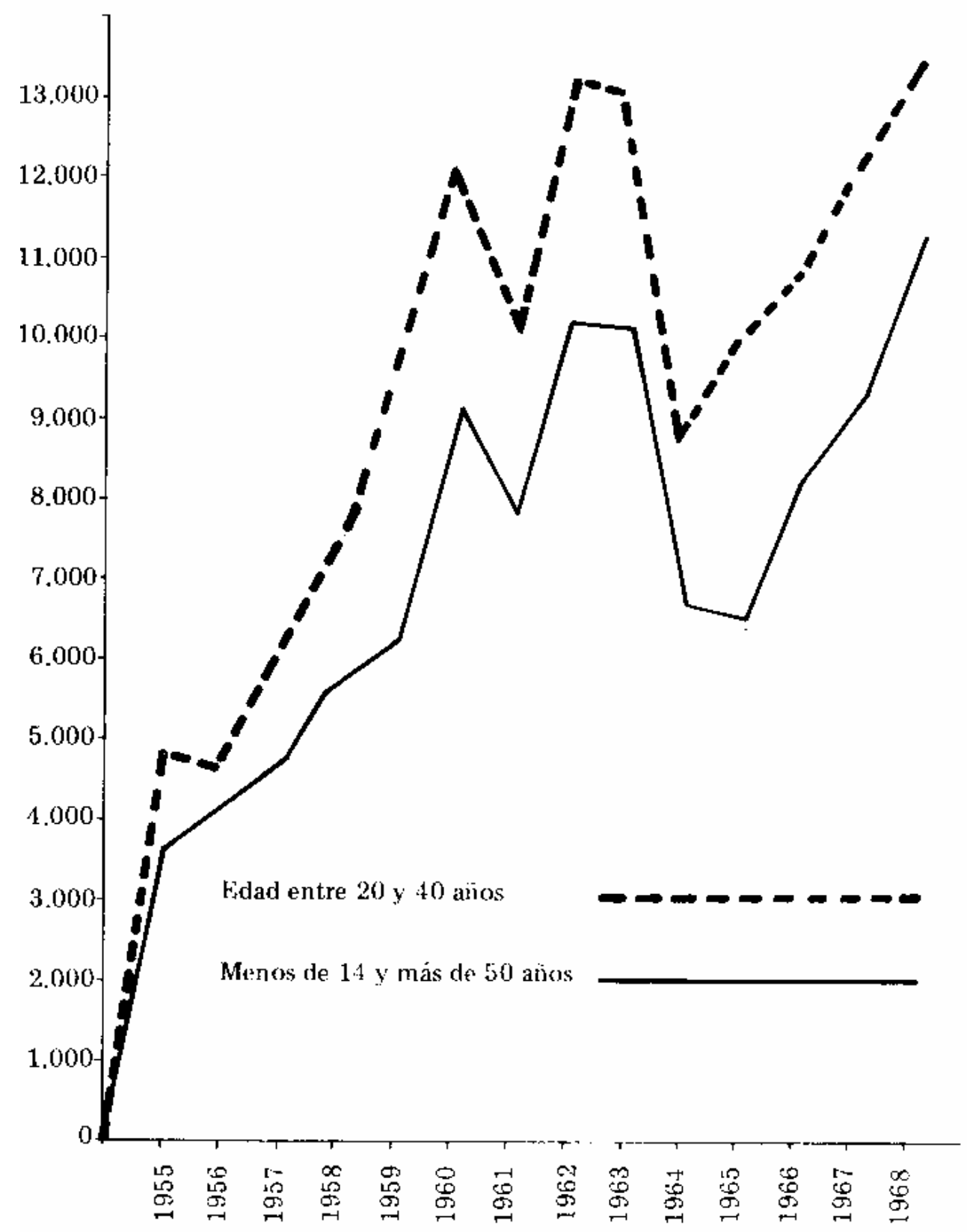

\section{Otras tendencias}

a) Regreso del personal altamente capacitado: Los ingenieros se encuentran entre los profesionales con mayor tendencia a regresar al país, siguen los educadores y los administradores. Es importante resaltar la alta tendencia de regreso de los médicos colombianos. 
b) Regreso del personal de nivel intermedio: Los técnicos industriales y mecanicos tienen la más alta tendencia al regreso, seguidos por los contadores y oficinistas.

\section{B. Factores determinantes de estas tendencias}

\section{Factores económicos}

Al analizar los factores que afectan positiva o negativamente la emigración del personal calificado a países más avanzados, hay que establecer ciertos criterios comparativos de naturaleza social y económica para la adecuada interpretación del problema.

Es evidente que algunos de los problemas sociales y económicos de los países en vía de desarrollo tienen características similares que se relacionan directamente con el problema emigratorio. Las diferencias sociales y la inestabilidad económica son los signos más notables del desequilibrio interno que lleva a la migración. Se reflejan estos problemas en la dependencia de la economía nacional de las más desarrolladas. Colombia es un ejemplo típico de esta situación, puesto que las variables sociales y económicas todavía no han alcanzado el punto de despegue.

El desequilibrio de los precios internos, la variabilidad de los términos de intercambio, el lento crecimiento del P.I.B., el aumento constante del déficit en la balanza de pagos, y en el crecimiento demográfico son los factores que más afectan actualmente los aspectos económicos de la migración.

La búsqueda de mejores oportunidades de trabajo y por lo tanto, mejores posibilidades de remuneración, es uno de los factores predominantes del problema migratorio del pueblo colombiano. Estas aspiraciones van al unísono con la rigidez que se observa en la estructura ocupacional, que perjudica directamente la diversificación del empleo.

\section{Factores educacionales}

Probablemente la causa más poderosa para la emigración de los colombianos se puede encontrar en la misma educación. De hecho, la tendencia educativa no ha sido orientada hasta ahora hacia el trabajo productivo, excepción hecha de las profesiones técnicas.

Precisamente esta circunstancia, ha sido la causa para que el país considere seriamente el establecimiento de los planes que lleven a un sistema educativo más adecuado. Teniendo en cuenta que el desarrollo de Colombia está basado en su capacidad de trabajo, es necesario hacer un diagnóstico correcto de la situación para orientar la producción educativa hacia los requisitos exigidos por la sociedad en general. La estructura económica colombiana, como se conceptualiza actualmente, no puede fácilmente asimilar esta producción mientras no se diversifique adecuadamente. La capacidad es tan reducida en ciertas áreas del conocimiento que la demanda sigue aumentando, produciéndose una brecha profesional, especialmente en aquellas profesiones que el país requiere con más urgencia.

Algunos de los factores educativos que afectan la salida de los profesionales colombianos fueron identificados en una encuesta de opinión, y se les puede resumir de la siguiente manera: 
a) El deseo de ascender a niveles profesionales superiores y adquirir nuevos conocimientos para desarrollar plenamente sus capacidades intelectuales.

b) La oportunidad de combinar la práctica profesional con el avance intelectual que algunas compañías extranjeras ofrecen.

c) La disponibilidad de institutos investigativos. Para compensar la fuga de cerebros y llenar la brecha tecnológica que separa a Colombia de los países más desarrollados, los educadores nacionales han recomendado aumentar la base de conocimientos del pueblo. La persona que adquiere conocimientos básicos, en vez de una técnica específica, puede adquirir rápidamente nuevas y diferentes técnicas; puede trabajar no solo con una clase de herramienta sino con varias, puede olvidar y aprender de nuevo, hasta el punto de ser científico o técnico. Es decir, es una persona que puede aplicar sus conocimientos, habilidades, y herramientas en su trabajo en una sociedad en vía de desarrollo para lograr los objetivos que él mismo ha establecido.

\section{Factores sociales}

En cada movimiento migratorio, es necesario analizar dos elementos básicos: la atracción y la repulsión. Las sociedades desarrolladas ejercen la atracción sobre algunos individuos que pertenecen a las sociedades en vía de desarrollo. Hay varios factores entre los cuales los más importantes son: la dependencia económica, el impacto cultural, un mejor nivel de vida, un sentido de seguridad más elevado, perspectivas más amplias para el avance intelectual, un rango más amplio de oportunidades de trabajo, etc.

En cambio, existe la repulsión por las condiciones existentes en la sociedad en vía de desarrollo, tal como la poca influencia que tiene la educación sobre la movilidad social. De hecho, se subestima la educación y tiene un valor diferente, comparado con la importancia que se le da en los países avanzados. Frecuentemente, es posible encontrar un abogado o un economista que se dedica tiempo completo a la preparación de declaraciones de renta, un ingeniero que trabaje en la agrimensura, un médico que trabaje como tecnólogo médico, etc.

Los factores estructurales internos enumerados son característicos de las sociedades tradicionales donde existen apenas dos o tres clases sociales y casi ninguna movilidad. En estas sociedades, hay diferentes valores sociales para evaluar a una persona -el sexo, la edad, la raza, los apellidos, la riqueza, las relaciones personales, etc. En cambio, en las sociedades modernas, la realización es el determinante más importante del éxito personal.

En la sociedad tradicional, el individuo frecuentemente no tiene interés en progresar porque da por hecho el éxito en su vida, o sea, a pesar de él. La educación en las sociedades tradicionales se toma como un bien de consumo, y no como una inversión real.

Colombia tiene algunos aspectos de este desequilibrio interno y se le puede definir como una sociedad de desarrollo interno con tendencia creciente hacia la modernización. Pero por ahora, la etapa de desarrollo autónomo está lejos, por lo cual se requiere una acción dinámica y continua de parte de la sociedad para aumentar la producción en vez del consumo. 
La movilidad social, entendida como el proceso de ascender y/o descender a los distintos estratos sociales, es demasiado restringida en el caso colombiano. Lentamente la educación se está convirtiendo en una de las principales fuentes de esta movilidad. Pero algunas de las personas educadas adquieren una conciencia social sui generis, realmente conciencia de grupo, con sus intereses respectivos y una tendencia a perpetuarse. Cuando la situación personal y de grupo de estos individuos no responde a sus intereses, empiezan a aparecer soluciones sociales que producen un cierto equilibrio individual. Estas soluciones sin embargo, pueden o no contribuir al desarrollo de esa sociedad. En el caso de Colombia, una de estas soluciones es salir del país, precisamente para buscar soluciones favorables para sus intereses.

Algunas de las motivaciones para quedarse en el país o emigrar fueron identificadas en una encuesta hecha con profesionales sobresalientes, en relación con el aspecto social, los interrogados estuvieron de acuerdo en que la estructura social colombiana no facilita la movilidad. Agregaron que la capacidad personal es un factor importante en la práctica profesional pero generalmente, esta capacidad debe ir ligada con conexiones sociales y políticas.

El factor principal para motivar el flujo emigratorio fue la falta de compromiso de los profesionales hacia la sociedad. La causa principal se atribuyó al contenido educativo ya que nunca se estudió la realidad del país con criterios sociales, científicos y técnicos. Bajo estas circunstancias, cuando los profesionales encuentran ciertos obstáculos en Colombia con relación a su práctica profesional de inmediato se inclinan a emigrar en vez de esforzarse por mejorar las condiciones existentes, como expresión de su conciencia social y nacionalista. La mayoría de los profesionales expresaron una cierta indiferencia con respecto a los problemas nacionales, pero deseaban que la universidad extendiera su influencia a la comunidad.

La creación de esta clase de identidad y conciencia nacional es más importante y efectiva que cualquier otro tipo de medidas legales coercitivas, tales como la obligación contractual para retener a los profesionales altamente calificados.

\section{Factores políticos}

No es una tarea fácil presentar un estudio detallado de los aspectos políticos con relación a la salida de la fuerza de trabajo profesional. Sin embargo, no se debe ignorar este problema.

En términos generales se puede decir que la raíz del problema radica en el hecho que la política de expansión educativa está estrechamente relacionada con el problema de crecimiento económico. Aunque es posible hablar de un proceso de interacción entre el crecimiento de la economía nacional, las oportunidades de empleo, y la expansión educativa, todo parece indicar que no se puede romper este círculo por el lado de la expansión educativa.

La verdad es que, tanto las incongruencias del sistema político como la falta de coordinación en las políticas de corto y largo plazo han producido una situación paradójica, entre las cuales, vale la pena mencionar el tema del presente estudio.

El sistema ha sido capaz de tomar medidas revolucionarias, por lo menos comparado con otros países del hemisferio, en relación a las oportunidades disponibles para una educación al nivel universitario y para una formación avanzada en el exterior. 
Desafortunadamente, este proceso no ha tenido la misma acogida por parte del sistema económico y social. Allí radica una de las incongruencias.

Por estas razones, se pueden enumerar algunas observaciones hechas para otros países pero aplicables a Colombia: a) Asimilación rápida de las primeras generaciones de la élite técnica y burocrática, un proceso que aumenta las expectativas de las generaciones subsiguientes.

b) Mayor restricción de la movilidad en la segunda generación. Quienes aspiraban pertenecer a la élite en esta segunda generación se dan cuenta que habían sobreestimado sus esperanzas. Además, se reducen las oportunidades para alcanzar un estatus social y económico elevado.

e) En muchas áreas, esta restricción puede crear inclusive una situación de desempleo, fomentando inevitables sentimientos de apatía, alienación y de destrucción de las estructuras de la sociedad.

d) Como resultado de la integración de la primera generación, debido a la presión ejercida por parte de la segunda generación sobre las élites técnicas y burocráticas, este sector emergente termina en conflicto con las élites políticas establecidas. Este conflicto ha sido claramente evidente durante los últimos cuatro años en Colombia. Gran parte del actual proceso político se centra en este hecho.

Claro está que dicha situación proviene de la falta de una solución del sistema social y económico a las demandas creadas por el sistema educativo. Como consecuencia, se produce la utilización de algunos mecanismos de respuesta a un sistema no capacitado para satisfacer las exigencias actuales. Tales mecanismos son: 1. La ubicación errónea de los recursos humanos, o la sub-utilización del talento. 2. La eliminación de la demanda de la fuerza de trabajo utilizando un método sencillo como el de promover su misma desaparición. En este caso, se ha tolerado la salida al exterior de la fuerza de trabajo profesional.

En realidad, se puede afirmar que el mecanismo de la salida de la fuerza de trabajo profesional tiene dos valores funcionales para el sistema porque:

1. Crea una solución al problema de desempleo para quienes emigran y por lo tanto, no se produce el proceso de frustración, alienación o extremismo político que sería de otra manera inevitable.

2. Se vuelve una expectativa o ilusión aceptable para aquellos que se quedan, contando con que siempre existe una puerta para escapar. Esta circunstancia previene o retarda el proceso de radicalización de dichos grupos.

Quizás dentro de esta doble funcionalidad se puede encontrar la razón por la cual estos países tan seriamente afectados por este desperdicio de talentos, han aceptado el convertirse en almacenes de provisión humana para los países más desarrollados.

En cierta forma no sería una exageración afirmar que hasta el momento, la salida de la fuerza de trabajo profesional ha significado una solución al problema que los mismos gobiernos no han podido solucionar. 
En general, se ha producido esta situación, como consecuencia inevitable, de la devaluación de la educación como agente movilizador. También se presenta la paradoja en la cual, precisamente los grupos más nacionalistas, aquellos que de una manera más enfática rechazan todas las formas colonialistas e imperialistas, quienes terminan siendo sujetos del desafortunado proceso de descapitalización nacional.

\section{Oportunidades para el progreso profesional y cultural}

La disminución del problema emigratorio, evidente en el análisis estadístico, se debe principalmente al hecho de que Colombia ha estado introduciendo cambios estructurales básicos en su sistema educativo.

Los cambios más importantes se refieren al contenido educativo y a la flexibilidad del currículum. Con respecto a la educación secundaria, se ha instituido un colegio secundario integral o vocacional y se han creado carreras intermedias o cursos de postgrado a nivel superior. Además, se elaboró un plan para aumentar el número de profesores universitarios con grados de Master o Ph.D. para los próximos cinto años.

Por lo que toca a la investigación, se ha creado un organismo especial llamado COLCIENCIAS para el desarrollo de la investigación científica y el Comité Nacional FORGE, Fondo para Educación y Becas de Investigación en el Exterior.

En relación con la democratización de la educación superior, se puede considerar a Colombia como el país más avanzado en América Latina por lo que toca a préstamos educativos, gracias a un sistema de redescuento que permite a los bancos comerciales suministrar los fondos necesarios a través de ICETEX.

En términos de la calidad de los programas mencionados, el ICFES (Instituto Colombiano para el Fomento de la Educación Superior) está desempeñando un papel importante al ofrecer los siguientes servicios:

a) Servicios a las universidades para la organización académica y administrativa.

b) Apoyo Financiero.

c) Unificación de los criterios de admisión.

d) Orientación profesional.

e) Integración regional.

f) Evaluaciones académicas permanentes, etc.

Los estudiantes colombianos pueden viajar ahora a los países más desarrollados con los programas de ICETEX ya sea a través de préstamos personales para educación superior en el exterior o de becas otorgadas por otros gobiernos, el ICETEX también ofrece oportunidades a los estudiantes extranjeros para estudiar en Colombia.

\section{Análisis en términos de costo-beneficio}

La fuga de cerebros causa tanto pérdidas en la inversión hecha en la educación de los emigrantes, como una disminución en el proceso de desarrollo de los países afectados. Esto se debe a la ausencia de la capacidad creativa y al efecto multiplicador del conocimiento. 


\section{A. Pérdidas de la Inversión en Educación y Entrenamiento}

Se estimó la pérdida neta de la fuerza de trabajo colombiano hasta 1968 en 20.506 profesionales según el Cuadro No. 12, es decir, 1.465 profesionales por año. Basándose en esta cifra, se estimó el costo total de la educación utilizando dos fuentes de información. La primera fue un estudio titulado, "Los efectos del desempleo sobre la tasa de retorno de inversiones educativas: Análisis del caso colombiano", que fue publicado por la Oficina Nacional de Planeación ${ }^{20}$. El segundo fue un análisis hecho por la Oficina de Planeación del ICFES. Teniendo en cuenta estos elementos, se logró el siguiente resultado:

a) Costo estimado por estudiante en la educación primaria (5 años)

b) Costo estimado por estudiante en la educación secundaria (6 años)

c) Promedio del costo estimado por estudiante en la educación superior (5 años)

TOTAL

$\$ 5.807 .00$

$\$ 7.002 .00$

$\$ 43.208 .00$

$\$ 56.077 .00$

Tomada la tasa de cambio en noviembre de 1969, \$17.62 por dólar, la suma total equivale a US \$3.182.60. Además, se debe tener en cuenta la devaluación anual de la moneda colombiana que es equivalente al $8 \%$ por año. Considerando el período educativo analizado (16 años), el costo real de educar a un profesional colombiano llega a una cifra cercana a los US $\$ 8.000$ y el costo de educar a un profesional de nivel medio es aproximadamente de US $\$ 2.000^{21}$. Con estas cifras, la pérdida neta causada por la emigración del nivel alto de la fuerza de trabajo colombiano, equivalente a la inversión educativa, asciende a US \$177.688.000; suma igual al presupuesto educativo del país para los últimos tres años.

Sin embargo, el verdadero costo de educar a un profesional colombiano que emigra no debería ser medido solo en términos de la inversión en su educación. El costo verdadero de esta pérdida se encuentra en la falta de contribución a la economía nacional y en el gran número de niños que se vieron privados del privilegio de la educación.

\section{Costo de educación y entrenamiento de los principales grupos de emigrantes}

Para calcular el costo de la educación y entrenamiento de los principales grupos emigrantes se tuvieron en cuenta los presupuestos universitarios del país, clasificándolos según los costos operativos y de inversión. Tanto los costos administrativos como los de las inversiones hechas en las instituciones fueron prorrateados entre el número de estudiantes por año. Las cifras correspondientes a los costos administrativos prorrateados se consideraron como costos indirectos.

\footnotetext{
${ }^{20}$ Marcelo Selowsky en "Revista de Planeación y Desarrollo", Volumen I, No. 2, Bogotá, julio 1969.

${ }^{21}$ Asumiendo que el nivel intermedio abarca once años de estudio, y que el número de emigrantes en este nivel fue de 6.820 .
} 
Cuadro No. 13

\section{COSTO DE LOS PRINCIPALES PROFESIONES RESPECTO A LA MIGRACION}

\begin{tabular}{|l|l|l|l|l|}
\hline \multicolumn{1}{|c|}{ Profesiones } & \multicolumn{2}{c|}{ Costo anual por profesional } & \multicolumn{2}{c|}{ Costo por toda la carrera } \\
\hline & & & & \\
\hline Agricultura y afines & 9.130 .000 & 512.17 & 45.650 .00 & 2.564 .10 \\
\hline Ciencias exactas & 9.575 .50 & 537.17 & 47.877 .50 & 2.689 .13 \\
\hline Ciencias Sociales & 8.705 .00 & 489.80 & 43.525 .00 & 2.445 .40 \\
\hline Derecho & 6.453 .20 & 362.96 & 32.266 .00 & 1.812 .12 \\
\hline Ingeniería y afines & 10.035 .00 & 563.14 & 50.175 .00 & 2.818 .14 \\
\hline Ciencias médicas & 9.666 .66 & 543.12 & 58.000 .00 & 3.258 .76 \\
\hline Educación & & & 25.382 .00 & 1.425 .17 \\
\hline
\end{tabular}

Las asignaciones correspondientes a costos operativos es decir, el costo de los sueldos de profesores, se consideran costos directos. Basándose en el procedimiento anterior, se calculó un estimativo anual de costo por estudiante.

La suma de los diferentes costos anuales permitió estimar el costo total de cada carrera profesional.

En el Cuadro No. 13 se indica tanto el costo anual por carrera profesional como el costo total. Se puede anotar que una de las carreras más costosas en el país es la medicina, seguida por la ingeniería y profesiones afines, las ciencias exactas y naturales, la agricultura y profesiones afines y las ciencias sociales. Las menos costosas son el derecho y la educación.

\section{Estimativo del costo de la educación en el exterior}

La cantidad total de dólares gastado por los colombianos en el exterior, durante el período analizado fue de US $\$ 57$. 100.000 .00 , lo cual corresponde a un promedio anual de US \$4.078.571.00 según el Cuadro No. 14. Este cuadro contiene la cantidad total de divisas invertidas en la educación de los estudiantes colombianos en el exterior, el promedio gastado por estudiante año por año, y la cantidad total durante el período.

El costo promedio en este período fue de US\$3.004.79. Se observa que en los últimos años ha habido un aumento en la inversión en dólares para estudios en el exterior. Mil novecientos sesenta y seis fue el año en que se invirtió la mayor cantidad de divisas y cuando se matricularon el mayor número de estudiantes colombianos en instituciones extranjeras de educación superior. El promedio de dinero gastado por persona durante ese año fue menor que el promedio estimado durante el período total.

Se tuvo que eliminar sin embargo, la cifra correspondiente a 1955 debido a la falta de suficientes datos estadísticos. Excluyendo este año, se estima que la suma por estudiante anualmente sube a US \$2 .655.80 durante el período total. Durante 1956, 1959, 1960 y 1961 el promedio es menor y el más bajo corresponde a 1961 equivalente a US \$845.50. La razón puede atribuirse al hecho de haber contado con un mayor número de becas parciales de otros gobiernos. 


\section{Salida de divisas por concepto de educación y entrada de divisas por el Comercio Exterior.}

La cantidad total de divisas en dólares enviados en este período alcanzó la suma US $\$ 57$. 100.00, mientras la entrada de divisas por las exportaciones colombianas durante el mismo período (1955-1968), alcanzó la cifra de US \$7.037.931.00. La proporción llega al $0.8 \%$ para el período completo o sea menos del $1 \%$ del ingreso total de las exportaciones colombianas. Vale la pena destacar el hecho de que el país gasta un mayor número de divisas en ciertos artículos como las bebidas alcohólicas y los cigarrillos.

\section{B. Pérdidas en la producción potencial}

La pérdida de talentos se refleja en la actividad económica en una disminución en el ingreso nacional. De hecho, se caracteriza la economía de un país por la producción, la distribución y el consumo de bienes y servicios. Además, en las dos últimas décadas, ha surgido la llamada "industria de conocimiento" que produce, distribuye y consume ideas, conceptos e información. Los economistas han hecho .un análisis de la participación de esta industria, en la formación del P.N.B. en los países avanzados en donde se estima que representa un cuarto del total.

Para calcular la pérdida potencial en la producción y en el consumo por la falta de participación de los emigrantes en la formación del P.N.B., se adoptaron dos vías: La primera determinando los posibles ingresos de los emigrantes, suponiendo que trabajaban en el país. La segunda calculando su contribución potencial a la formación del P.N.B.

a) Ingresos potenciales de los emigrantes: Por dificultades metodológicas para fijar las escalas salariales a los profesionales en el sector privado, fue necesario utilizar la estructura salarial correspondiente al sector público. Utilizando esta base se pueden preveer resultados aceptables, ya que el gobierno es el mayor empleador de la fuerza de trabajo profesional.

En el Cuadro No. 15 se muestra la pérdida del país en sueldos potenciales que pudieran haber ganado los emigrantes. Estas pérdidas alcanzan \$1.253.915.236.00 lo cual corresponde a US \$71.164.315.00 o el 4.4\% del Ingreso Nacional en 1967.

La suma es significativa teniendo en cuenta que afecta el poder de consumo y éste a su vez y directamente el nivel de producción, y como consecuencia, el nivel de empleo.

b) Contribución potencial al P.N.B.: Para estimar la pérdida causada al país por la ausencia de los emigrantes profesionales, se utilizó el siguiente método. 


\section{CANTIDAD DE DIVISAS GASTADAS EN EDUCACION DE COLOMBIANOS EN EL EXTERIOR (1955- 1960)}

\begin{tabular}{|c|c|c|r|}
\hline Año & $\begin{array}{l}\text { Giro en US \$ para } \\
\text { estudiantes en el } \\
\text { extranjero }\end{array}$ & $\begin{array}{l}\text { Número de } \\
\text { estudiantes } \\
\text { universitarios en el } \\
\text { extranjero }\end{array}$ & $\begin{array}{l}\text { Promedio US \$ } \\
\text { gastados } \\
\text { por estudiante }\end{array}$ \\
\hline 1955 & 6.900 .000 .00 & $101^{22}$ & 68.316 .83 \\
\hline 1956 & 4.600 .000 .00 & 2.467 & 3.417 .61 \\
\hline 1957 & 3.100000 .00 & 907 & 3.31675 \\
\hline 1958 & 2.000 .000 .00 & 603 & 2.178 .42 \\
\hline 1959 & 2.100 .000 .00 & 964 & 84550 \\
\hline 1960 & 1.500 .000 .00 & 617 & 2.883 .80 \\
\hline 1961 & 2.200000 .00 & 2.602 & 3.292 .18 \\
\hline 1962 & 3.400 .00000 & 1.179 & 2.832 .03 \\
\hline 1963 & 3.200 .000 .00 & 972 & 2.97357 \\
\hline 1964 & 2.900 .000 .00 & 1.024 & 3991.00 \\
\hline 1965 & $5,700.000 .00$ & 1.973 & 3.04133 \\
\hline 1966 & 8.100 .000 .00 & 2.724 & 3.004 .79 \\
\hline 1967 & 7.100 .000 .00 & 1.779 & \\
\hline 1968 & 4.300 .000 .00 & 1.091 & \\
\hline & & &
\end{tabular}

Fuente: Banco de la República.

Promedio anual: 4.078.571,00

\footnotetext{
${ }^{22}$ La cifra para este año corresponde solo a aquellos estudiantes que disfrutaron de becas del ICETEX. Solamente en 1956 se autorizó al Instituto para girar divisas a los estudiantes colombianos en el exterior.
} 
Cuadro No. 15

\section{PERDIDAS DE SALARIOS POTENCIALES DEBIDO A LA EMIGRACION 1964}

\begin{tabular}{|l|r|r|r|r|}
\hline Áreas de estudio & \multicolumn{1}{|c|}{$\begin{array}{c}\text { Salario } \\
\text { promedio } \\
\text { mensual }\end{array}$} & \multicolumn{1}{c|}{$\begin{array}{c}\text { Salario } \\
\text { promedio } \\
\text { anual }\end{array}$} & \multicolumn{1}{c|}{$\begin{array}{c}\text { Emigrantes } \\
\text { netos }\end{array}$} & \multicolumn{1}{c|}{$\begin{array}{c}\text { Pérdida anual } \\
\text { en salarios }\end{array}$} \\
\hline $\begin{array}{l}\text { Agricultura y } \\
\text { afines }\end{array}$ & 4.535 & 63.490 & 404 & 25.649 .960 \\
\hline Bellas artes & 3.070 & 42.980 & 2.212 & 95.071 .760 \\
\hline Ciencias exactas & 4.892 & 68.040 & 1.033 & 70.285 .320 \\
\hline Ciencias sociales & 3.785 & 52.990 & --- & --- \\
\hline Derecho & 4.535 & 63.490 & 1.008 & 63.997 .920 \\
\hline Educación & 4.940 & 69.160 & 1.830 & 126.562 .800 \\
\hline Humanidades & 4.785 & 66.990 & --- & -- \\
\hline Ingeniería & 4.892 & 68.488 & 6.667 & 456.609 .495 \\
\hline Ciencia médicas & 4.535 & 63.490 & 2.491 & 158.153 .590 \\
\hline $\begin{array}{l}\text { Economía y } \\
\text { administración }\end{array}$ & 3.785 & 52.990 & 4.861 & 257.584 .390 \\
\hline
\end{tabular}

Fuente: ICETEX

Col. \$1.253.915.236

US $\$ 71.164 .315$

- Basado en el censo demográfico de 1964, se hizo un perfil educativo según niveles de educación de la población económicamente activa.

- Se calculó el costo de cada nivel educativo según la moneda colombiana en el año 1964.

- Se calculó el costo total de los estudios con respecto a la población económicamente activa de 1964, teniendo en cuenta que las personas clasificadas como "otros niveles" tenían un promedio de cuatro años de educación primaria.

- Se consideró el costo total de estudios como una inversión y el P.N.B. de 1964 como el producto de tal inversión, estimando que la proporción entre los dos fuera el coeficiente que indicara la proporción en la cual la inversión educativa contribuye a la formación del P.N.B.

NOTA: $\quad$ Rei = Coeficiente de Rentabilidad para la Inversión Educativa.

$$
\begin{aligned}
& \text { Cei }=\text { Costos educativos para la población } \\
& \text { económicamente activa en } 1964 . \\
& \text { Rei }=\underline{\text { P.N.B. } 1964 \text { Col\$ 50.457.200.000.00 }}=1.4 \\
& \text { Cap. 1964 Col\$ 34.945.703.390.00 }
\end{aligned}
$$

Por lo tanto, Rei $=1.4$ 
- Los costos estimados para cada área de estudio se llevaron a pesos de 1964. Al multiplicar estos costos por el coeficiente de rentabilidad de la inversión educativa, 1.4, se obtiene la contribución potencial por profesión, en la formación del P.N.B.

Luego se relacionó la cifra neta del alto nivel de emigración (Ver Cuadro No. 12) con la contribución potencial de cada profesional, para estimar la pérdida total causada por la fuga de cerebros.

- Se estimó que el costo educativo para un emigrante de nivel intermedio pudo ser asimilado al costo de educar a un estudiante de secundaria, debido a la falta, casi total, de entrenamiento vocacional post-secundaria en el país. Este costo estimulado es de Col.\$12.809.00. El coeficiente de rentabilidad de 1.4 que se utiliza aquí indicará una pérdida potencial por persona con nivel intermedio es de \$17.933.00. La pérdida total causada por los 6.820 emigrantes de este nivel asciende a \$122.196.240.00, equivalente a US $\$ 69.407 .000 .00$.

En resumen, la pérdida total potencial sufrida por el país en el período estudiado por la falta de contribución de los emigrantes a la formación del P.N.B. se puede estimar en \$1.879.307.351.00, equivalente a US \$106.657.600.00. Esta suma es mayor que los préstamos exteriores otorgados a Colombia en 1968 que sumaron a US \$77.973.800.00.

\section{Embotellamientos de la fuerza de trabajo y migración profesional}

En el análisis anterior, se hizo un estimativo cuantitativo de las incidencias potenciales del problema migratorio en el consumo y la producción. La pérdida potencial estimada implica que podría haber posibilidad de trabajo productivo para todos los emigrantes. No siempre es el caso, porque se deben considerar tanto las características recesivas de la economía como la rigidez de la inversión que, en la mayoría de los casos, no solo produce diferentes problemas en la generación de nuevos empleos sino que disminuye su demanda. Esto ocurre por la substitución del trabajo por capital como ha estado ocurriendo en el país en los últimos años en varias actividades industriales tales como el tabaco, los muebles de madera, el caucho, los subproductos del petróleo, el carbón y las industrias metálicas básicas.

Cuando la actividad económica no tiene la capacidad suficiente para proveer trabajo productivo a todos los graduados se favorece directamente la emigración del personal de alto nivel. Como consecuencia, hay una incidencia desfavorable en los niveles de consumo y producción y en la generación de nuevos trabajos.

\section{Factores culturales que afectan la utilización de la fuerza de trabajo profesional}

Aunque es difícil medir el determinante cultural y su efecto en la utilización de la fuerza de trabajo profesional, la experiencia de quienes han regresado permite identificar algunos factores.

El primer factor se refiere al proceso vivido por los estudiantes provenientes de países en desarrollo como Colombia, cuando llegan a las sociedades avanzadas y encuentran nuevos valores culturales, diferentes a los de la cultura donde recibieron su socialización.

Surgen un sin número de necesidades que nunca antes se sintieron. Estas nuevas necesidades encuentran soluciones adecuadas dentro del ambiente avanzado que las creó. Al principio se les da una importancia relevante y luego son asimiladas. El resultado 
lógico es que cuando los emigrantes vuelven de nuevo a sus comunidades no encuentran esas "nuevas necesidades" y por lo tanto, las respuestas aprendidas en una sociedad más avanzada carecen de sentido.

Estas necesidades se manifiestan principalmente en los indicadores culturales tales como la disponibilidad de revistas, periódicos y libros especializados y en los medios de comunicación. Por lo ausencia casi total de estos elementos, el recién graduado no es capaz de readaptarse a su viejo ambiente; subestima sus propias costumbres y por lo tanto se siente desubicado.

Este proceso conduce a la frustración, la destrucción de la estructura de la sociedad, el conflicto de intereses, etc., afectando, como se índice anteriormente, su potencial económico.

\section{Ventajas de la emigración de la fuerza de trabajo especializado}

Sería absurdo decir que el problema emigratorio solo produce desventajas para el país. Esta declaración sería tan arriesgada como decir que el factor emigratorio es provechoso. No se puede analizar este fenómeno sin tener en cuenta el actual período histórico o las actuales características económicas y sociales. Todos estos factores contribuyeron a la emigración, aumentándola o disminuyéndola como se muestra en el Cuadro No. 6.

En la primera parte de este capítulo, se mencionaron algunos efectos desfavorables como las pérdidas potenciales. Algunos de los efectos favorables son los siguientes:

\section{Ingresos recibidos de los nacionales residenciados en el exterior}

En la mayoría de los casos se encuentra que los emigrantes alcanzan un nivel salarial y un nivel de vida más alto que el que hubieran tenido en el país. Se puede agregar que los giros enviados por los emigrantes a sus familiares en Colombia constituyen no solo un flujo benéfico de divisas sino que además tiende a aumentar el nivel de consumo de quienes lo reciban.

\section{Transferencias de oportunidades negocios, conocimientos, tecnología y ciencia}

Quienes mantienen sus contactos en el país de origen y además crean nuevos en el país de destino se convierten en medio de transporte para diferentes programas de intercambio. La clase y volumen de estas actividades dependerán del campo de actividad, puntos de interés, y contactos que adquiera el emigrante. Si este es un ejecutivo con experiencia o un socio de una firma comercial o industrial, surgirán oportunidades de intercambio en el campo de los negocios o actividades productivas o en utilización de nuevos equipos, lo cual implica transferencia de tecnología. A su vez, el profesor universitario o el científico, promoverán la transferencia dentro del área de conocimiento de su especialidad. En el caso de un ingeniero, técnico o especialista en la investigación aplicada, la transferencia será en el campo tecnológico. Las cifras de comercio exterior son correlativas a los países seleccionados por los emigrantes colombianos. Se puede considerar este hecho un indicador que refuerza las ideas expresadas anteriormente. 


\section{Porcentaje de personas que permanecen en Colombia por imposibilidad de emigrar}

En la encuesta hecha entre algunos de los estudiantes que volvieron al país después de estudiar en el exterior, se trató de medir la emigración potencial preguntándoles si deseaban emigrar. El $57 \%$ de los entrevistados esperaban emigrar aunque aún no habían determinado la fecha. Del total, el $50 \%$ había trabajado en el exterior mientras estudiaban y opinaban que hubieran podido tener un mejor rendimiento en el exterior que en su propio país de origen. Del número total de entrevistados, el $40 \%$ piensa emigrar definitivamente, y el $12 \%$ lo haría si esto significara mayores ingresos y un mejor nivel de vida para sus familias. El $43 \%$ piensa quedarse en Colombia.

\section{Porcentaje de personas que vuelven al exterior por carencia de empleo en Colombia}

Es difícil decir que el problema emigratorio es un fenómeno derivado del desempleo o que hay personas que están obligadas a volver al exterior porque no encuentran empleo en Colombia. Basados en la misma encuesta y por carencia de otras fuentes, se calculé el nivel de desempleo tomando el tiempo requerido para encontrar trabajo. El $41 \%$ de los entrevistados consiguió empleo en menos de un mes; el $53 \%$ se demoré de uno a cuatro meses y apenas el 6\% más de seis meses. El ideal sería analizar los niveles ocupacionales y se espera que habrá más información disponible en el futuro, cuando se tengan los datos de la oficina de empleo y recursos humanos cuyo fin principal es el de proveer de empleo a los profesionales entrenados en el exterior. Se puede asumir que por lo menos el $6 \%$ se inclina a regresar al país en donde estudió ya que no encuentra el trabajo apropiado en Colombia.

\section{Estudiantes nacionales en las mismas áreas y niveles de aquellos que estudian en el exterior.}

En el cuadro No. 16 se indica tanto el número de estudiantes matriculados en los Institutos Superiores de Colombia como el número de estudiantes en el exterior, por áreas de estudio. También se presentan las relaciones entre estos dos grupos, año por año, en la siguiente manera:

a) La relación más estrecha entre estos grupos se encuentra en el campo de las ciencias exactas y naturales con el $19 \%$ y a continuación las ciencias sociales, las humanidades y la educación. La relación más dispar se encuentra en las carreras intermedias, la medicina y la ingeniería que por otro lado proporcionan el mayor número de emigrantes.

b) Durante el período estudiado, por cada 100 estudiantes universitarios en el país, había 4 en el exterior. Se pueden identificar tres períodos en donde dicha relación era mayor. En 1956 era de 100 a 16, en 1961 de 100 a 10 y de 100 a 6 en 1966.

c) Los estudiantes colombianos ingresan a las universidades nacionales principalmente en los campos de ingeniería, medicina y derecho, y a las extranjeras en las áreas de ingeniería, ciencias sociales, medicina y educación. 


\section{Fuerza de trabajo nacional que está sustancialmente desempleada o} subempleada

La subutilización del talento toma dos formas: el desempleo y el subempleo. Se puede medir la primera objetivamente y la segunda subjetivamente.

\section{CUADRO No. 16 \\ ESTUDIANTES NACIONALES EN LAS MISMAS AREAS Y NIVELES DE AQUELLOS QUE ESTUDIAN EN EL EXTERIOR} (1955 -1958)

\begin{tabular}{|c|c|c|c|c|c|c|c|c|c|c|c|c|}
\hline \multirow[t]{2}{*}{$\begin{array}{l}\text { Áreas de } \\
\text { estudio }\end{array}$} & \multicolumn{3}{|c|}{1955} & \multicolumn{3}{|c|}{1956} & \multicolumn{3}{|c|}{1957} & \multicolumn{3}{|c|}{1958} \\
\hline & Extranjeros & Nacionales & $\begin{array}{c}\% \\
\text { W.N }\end{array}$ & Extranjeros & Nacionales & $\begin{array}{c}\% \\
\text { E.N }\end{array}$ & Extranjeros & Nacionales & $\begin{array}{c}\% \\
\text { E.N }\end{array}$ & Extranjeros & Nacionales & $\begin{array}{c}\% \\
\text { E.N }\end{array}$ \\
\hline $\begin{array}{c}\text { Agricultura y } \\
\text { afines }\end{array}$ & 9 & 426 & 2.11 & 266 & 576 & 46.18 & 82 & 705 & 11.6 & 55 & 926 & 5.9 \\
\hline Bellas artes & 4 & 892 & 0.45 & 96 & 918 & 10.45 & 36 & 1.089 & 3.3 & 24 & 1.058 & 2.3 \\
\hline $\begin{array}{c}\text { Ciencias } \\
\text { exactas }\end{array}$ & 9 & 156 & 5.77 & 271 & 329 & 82.37 & 109 & 431 & 25.3 & 72 & 536 & 13.4 \\
\hline $\begin{array}{c}\text { Ciencias } \\
\text { sociales }\end{array}$ & 11 & 594 & 1.85 & 280 & 667 & 41.97 & 154 & 749 & 20.6 & 103 & 24 & 12.2 \\
\hline Derecho & 8 & 2.443 & 0.33 & 192 & 4.679 & 7.16 & 18 & 3.011 & 0.6 & 12 & 3.466 & 0.3 \\
\hline Educación & 13 & 358 & 3.63 & 293 & 475 & 61.6 & 110 & 544 & 20.2 & 72 & 648 & 11.1 \\
\hline Humanidades & 9 & 547 & 1.64 & 215 & 601 & 35.7 & 64 & 698 & 9.26 & 42 & 790 & 5.3 \\
\hline $\begin{array}{c}\text { Ingeniería y } \\
\text { afines }\end{array}$ & 20 & 2.958 & 0.67 & 298 & 3.432 & 8.7 & 181 & 3.879 & 4.6 & 120 & 4.691 & 2.5 \\
\hline $\begin{array}{l}\text { Ciencias } \\
\text { médicas }\end{array}$ & 13 & 4.452 & 0.29 & 285 & 4.569 & 6.2 & 108 & 4.583 & 2.3 & 73 & 4.735 & 1.5 \\
\hline $\begin{array}{c}\text { Carreras } \\
\text { intermedias }\end{array}$ & 5 & 961 & 0.52 & 153 & 1.079 & 14.1 & 25 & 1.201 & 2.1 & 20 & 1.349 & 1.5 \\
\hline Otros & --- & --- & --- & 118 & 220 & 53.6 & 20 & 50 & 40.0 & 10 & 59 & 16.9 \\
\hline Total & 101 & 13.787 & 0.73 & 2.467 & 15.545 & \begin{tabular}{|l|}
15.8 \\
\end{tabular} & 907 & 16.940 & 5.3 & 603 & 19.099 & 3.1 \\
\hline$\%$ & 0.53 & 3.04 & --- & 13.0 & 3.43 & --- & 4.8 & 3.74 & --- & 3.17 & 4.21 & --- \\
\hline
\end{tabular}

El Centro de Investigaciones de la Universidad de los Andes (CEDE) elaboré una encuesta con respecto al desempleo en las principales ciudades en el país y encontró los siguientes porcentajes del desempleo profesional en relación con la suma total de desempleados: Bogotá, 3.2\%; Medellín, 3.9\%; Cali, 1.1\%; Barranquilla, 2.7\%; Bucaramanga, 5.7\%; Manizales, 4.8\%. La media aritmética para estas ciudades es del $3.2 \%$ y el promedio estimado del desempleo profesional para todo el país es del $4 \%$. Se aclara que un profesional desempleado es aquel que no trabaja ni una hora diaria.

Basándose en esta información, es necesario decir que el problema del desempleo profesional en Colombia no es tan serio, sí se tiene en cuenta que la encuesta de CEDE reveló que el nivel general de desempleo en el país era del $8.8 \%$ de la población económicamente activa. Es decir, por cada 1.000 personas económicamente activas, hay 88 desempleados, de los cuales 3 son profesionales. En los países en vía de desarrollo, donde algunas medidas de expansión en la economía conducen a la inflación, el desempleo estructural' puede ser más alto que en los países desarrollados. En Colombia, el nivel de desempleo estructural corresponde al 6 ó 7\%, aproximadamente, comparado con el 3 ó $4 \%$ en los Estados Unidos.

En cambio, parece que el problema más serio en Colombia a este respecto es el subempleo profesional. Esto es significativo cuando se observa que los profesionales tienen que aceptar empleos que no están a la altura de sus capacidades intelectuales. Los investigadores del CEDE midieron el subempleo calculando el número de hombre-horas disponibles en la fuerza de trabajo y el número de horas desperdiciadas. Así concluyeron 
que el subempleo total en el país llega al 9.6\%. Esta cifra es bastante alta. El subempleo profesional es importante porque existen muchas quejas con relación a la baja productividad y a los bajos niveles salariales en la actividad económica del país. Esta situación conduce a ocupaciones marginales y, por lo tanto, a la emigración.

\section{IV.Las respuestas de la política gubernamental}

\section{A. La política gubernamental ante el problema}

Aunque no existe una legislación clara referente a la emigración de los profesionales colombianos, se puede decir que sí existe una política gubernamental. Recientemente el Presidente de Colombia declaró: "es la obligación de cada ciudadano colombiano ofrecer sus conocimientos al servicio del país, aunque sea únicamente por el honor de ser colombiano, y prestar un servicio a su país ${ }^{23}$.

Esta política se manifiesta en las siguientes actividades:

\section{Cursos de Post-grado}

En 1968, el Congreso autorizó poderes extraordinarios al Presidente para modernizar la administración pública colombiana. Como consecuencia, se crearon dos nuevas instituciones orientadas a una mejor utilización de la fuerza de trabajo profesional. La primera es el Instituto Colombiano para el Fomento de la Educación Superior, ICFES, que ha promovido la organización de programas de post-grado en las universidades locales. Esto generará empleos para los profesionales que tienen un grado de masters o Ph.D. y también hasta cierto grado reemplazar la importación de profesionales extranjeros con el fin de elevar el nivel académico de los profesionales en Colombia. Se creó un Comité de Estudios de Post-grado con los siguientes objetivos:

a) Elaborar un inventario de los cursos de post-grado ofrecidos en el país.

b) Organizar y promover la fundación de escuelas de post-grado en el sistema educativo colombiano, y

c) Incentivar la repatriación de los científicos colombianos que han emigrado.

Hasta el presente los estudios de post-grado de mayor crecimiento han sido los de ciencias médicas. De hecho, se pueden adelantar especializaciones en todos los campos de la medicina en los distintos hospitales del país. Simultáneamente, se han organizado otros programas de post-grado, especialmente en el campo de la agricultura, como resultado del esfuerzo conjunto entre la Universidad Nacional y el Instituto Colombiano Agropecuario, ICA, Lo mismo que post-grados en ingeniería y ciencias sociales, sin embargo, todavía Colombia no ofrece ningún programa de Ph.D. y ni siquiera se encuentra en organización.

Otra institución que también contribuye al desarrollo de la educación superior es la Fundación Colombiana para Ciencia y Tecnología, COLCIENCIAS. Hasta el presente, ha delineado un esquema para atraer al personal científico colombiano que trabaja en el exterior con el fin de reincorporarlos a las actividades investigativas y pedagógicas en las universidades. Se espera lograr los siguientes objetivos con el programa:

\footnotetext{
${ }^{23}$ Aparte del discurso del Presidente de Colombia en la conmemoración del aniversario del ICETEX, 1967. Digitalizado por RED ACADEMICA
} 
- Satisfacer la necesidad de profesionales en ciertas áreas del conocimiento, específicamente en la ciencia y la tecnología.

- Contar con una fuerza de trabajo altamente calificada para el desarrollo de programas que conducen tanto al mejoramiento de la educación científica como a la modernización de los métodos de enseñanza en los niveles secundarios y universitarios.

- Trabajar tanto por el regreso de los científicos colombianos que actualmente están en el exterior, como para su re-adaptación al país.

La implementación de este programa es responsabilidad de COLCIENCIAS y un grupo asesor con la participación del Ministerio de Educación, ICFES, ICETEX, dos Fundaciones Nacionales privadas, la Fundación FORD, y la US National Science Foundation.

COLCIENCIAS está investigando la demanda de fuerza de trabajo a alto nivel para identificar las áreas en las cuales se requiere el regreso de profesionales. Quienes regresen firmarán un contrato por tres años en donde aceptan prestar los servicios requeridos bajo las siguientes condiciones:

a) El científico será nombrado profesor universitario o investigador y al mismo tiempo miembro del Consejo Asesor de COLCIENCIAS.

b) COLCIENCIAS se compromete a pagar un sueldo adicional de US $\$ 6.000$ y un subsidio de transporte e instalación de US \$1.500.00. Además se pagarán los gastos de viaje del candidato, su esposa e hijos.

c) La institución donde trabaje el candidato le asignará el sueldo que corresponde a la clase de trabajo que desempeñe.

d) COLCIENCIAS negociará con el gobierno la exención de impuestos aduaneros para la importación de los muebles y otros artículos caseros, y del vehículo de uso particular.

Al terminar el período de tres años, se considerará la renovación del contrato bajo condiciones similares.

Se esperan dos tipos de beneficios de este programa:

-Beneficios tangibles o directos: Estos se pueden medir por el número de personas que disfrutarán del programa de enseñanza y por el aporte científico en los cursos de vacaciones, seminarios, etc.

-Beneficios indirectos: Consisten en la incorporación de un selecto grupo de profesionales a la comunidad científica colombiana. Será un hecho la mejora en la calidad de enseñanza, en aquellos centros donde se integren los profesores. Además, los equipos y servicios actualmente subutilizados serán más productivos. Otro beneficio indirecto será la creación de un ambiente propicio para el desarrollo científico, punto central de atracción para otros científicos jóvenes de Colombia y Latinoamérica, actualmente dispersos por falta de un ambiente adecuado. 


\section{Servicio de empleo}

Otra medida legislativa importante sancionada por el gobierno es la organización de un servicio de empleo como nueva unidad del ICETEX para quienes regresen. En esta unidad se coordinan las posibilidades ocupacionales en los niveles salariales más altos para las personas más capacitadas. Se propician contactos necesarios con empleadores potenciales a través de un boletín mensual en donde se presenta la demanda actual de profesionales que han regresado al país o que deseen cambiar sus puestos actuales.

\section{Incentivos salariales}

Finalmente, dentro de las medidas adoptadas por el gobierno para reformar la administración pública, se incluyeron una serie de normas para reformar los niveles salariales de profesionales y técnicos, además de la sanción del decreto que mejora los sueldos del sector público, la aprobación de la prima técnica extra, consistente en un aumento del $50 \%$ del salario normal, de acuerdo con la competencia y experiencia profesional. Esta medida ha permitido que muchos profesionales colombianos regresen al país después de haber ocupado posiciones importantes en organizaciones internacionales.

\section{B. Perspectivas y actitudes expresadas en el gobierno con respecto al problema}

Durante el seminario "Controversia sobre Colombia", que se realizó en julio de 1966, varios empleados del gobierno señalaban la seriedad del problema migratorio, en lo referente a la fuerza de trabajo profesional. Esta inquietud surgió de la visita al país del doctor Charles V. Kidd de la Oficina de Ciencia y Tecnología, Oficina Ejecutiva del Presidente de los Estados Unidos. Varios periódicos publicaron editoriales sobre el tema y expresaron: "Estamos seguros que las autoridades educativas nacionales conocen bien los hechos; además, presumimos que se siente la gravedad de la situación a todo nivel gubernamental. Es equivalente a la exportación masiva de capital. Pero este capital es tanto humano como monetario, representado por el dinero invertido en el entrenamiento de estos profesionales; es un éxodo de riqueza que afecta profundamente al futuro de la Nación".

En otro editorial el Ministro de Educación comentó el problema en la siguiente manera:

"En el problema de la emigración del talento nacional, entra en juego tanto el incentivo económico como la atracción científica. Pero aún existe otro factor característico de nuestro país -la desilusión experimentada por los estudiantes universitarios, debido a las limitadas oportunidades de investigación y a la deficiencia de ciertos programas académicos. Para buscar una solución y reducir el problema migratorio, el primer paso debe ser una evaluación a fondo del sistema educativo y la creación de incentivos permanentes por parte del sector privado, las instituciones culturales, y el gobierno, con el fin de poder utilizar a nuestros profesionales".

Pero la opinión más representativa del gobierno fue la expresada por el mismo Presidente Lleras en octubre de 1967, cuando dijo: "Es más patriótico trabajar para Colombia que abandonar las obligaciones impuestas a los profesionales y salir a servir a sociedades más desarrolladas que la nuestra". 
Al mismo tiempo el Presidente defendió al ICETEX por ser instrumento para el logro de "una comunidad más igualitaria a través de la igualdad de oportunidades educativas" 24

Más recientemente, algunos representantes oficiales del país que asistieron al foro para la creación de mercado económico sub-regional, "El Grupo Andino", declararon que uno de los objetivos del nuevo esfuerzo de integración fue la ampliación de oportunidades de empleo para profesionales, puesto que la integración lograría una industrialización completa"25.

En el mismo año, 1968, se anunció un plan importante para contrarrestar la fuga de cerebros en el campo de la medicina, utilizando los recursos nacionales para la salud en todas las áreas geográficas y sociales del país. La iniciativa nació en la Escuela de Medicina de la Universidad Nacional, el Ministerio de Salud, el Instituto Colombiano de Seguros Sociales y la Academia Nacional de Medicina con la colaboración de la Asociación Colombiana de Escuelas de Medicina y otras instituciones importantes. El plan consiste en ofrecer mayores oportunidades de trabajo, mejores sueldos y la ampliación del mercado para médicos que se gradúen de las diferentes universidades del país.

\section{El papel de las organizaciones privadas}

La educación y la utilización de la fuerza de trabajo profesional son problemas que no solo interesar al gobierno. Las organizaciones privadas también comparten la responsabilidad específicamente en lo que se refiere a la unión de esfuerzos para reducir la emigración profesional.

En el caso de Colombia, se deben concentrar estos esfuerzos en la expansión y el mejoramiento del sistema educativo y en el desarrollo de oportunidades de empleo y trabajo "bien remunerados" para los profesionales colombianos.

El papel básico de las organizaciones privadas está ligado con la cantidad y calidad de la educación. En el aspecto cuantitativo, la tendencia universal muestra un mayor desarrollo de la educación pública a medida que aumenta en forma acelerada las matrículas en las instituciones privadas de educación superior: En 1955, por ejemplo, la educación privada superior producía el 38\% de los graduados y esta participación ha aumentado en la última década, el $48 \%$.

Se puede apreciar mejor la dinámica de las universidades privadas en Colombia al estudiar los porcentajes comparativos de matrículas estudiantiles entre 1955 a 1968.

En los últimos 5 años se han establecido varias fundaciones y corporaciones privadas para contribuir a la financiación de la educación superior. Entre estos vale la pena mencionar a la Fundación para Educación Superior (FES), que complementa los sueldos de los profesores universitarios de una universidad pública importante con fondos suministrados por la comunidad. Con este esfuerzo los sueldos se vuelven altamente competitivos aún a nivel internacional.

La contribución de las universidades privadas para la producción de la fuerza de trabajo profesional en Colombia es más evidente al observar la baja productividad del sistema educativo nacional y la gran brecha científica y tecnológica.

\footnotetext{
4 "El Espectador" julio 18, 1966.

"El Tiempo"agosto 29, 1967. 
Además, el contenido de muchos programas profesionales se obsoletiza debido a la lentitud en la adaptación de estos programas al proceso de cambios e innovaciones científicas. Por estas razones, el país enfrenta problemas críticos con la utilización deficiente de su fuerza de trabajo profesional. Como respuesta lógica a esta situación irregular se han adoptado varias soluciones por medio de reglamentaciones gubernamentales.

\section{A. La política del gobierno sobre el contrato de los profesionales colombianos}

La protección de las condiciones laborales para los nacionales es una medida común en la mayoría de los países del mundo.

La constitución de Colombia establece la igualdad de los derechos civiles para nacionales y extranjeros y autoriza al legislador para imponer condiciones especiales 0 negar el ejercicio de ciertos derechos a los extranjeros que trabajen en el país.

EI Derecho Laboral prescribe que cuando la empresa tiene más de 10 trabajadores, los empleadores deben enganchar no menos del $90 \%$ de mano de obra colombiana no calificada y el $80 \%$ de mano de obra colombiana especializada o de personal administrativo.

En el caso de la exploración y explotación de la industria petrolera en donde las compañías extranjeras introducen una cantidad considerable de capital y tecnología, la legislación protege a los nacionales colombianos para que se empleen bajo las mismas condiciones y con los mismos sueldos que los trabajadores extranjeros.

Además en los antiguos estatutos del Servicio Civil, el primer requisito para ser aceptado en esta carrera era el de ser colombiano por nacimiento o adopción. Sin embargo, la reforma administrativa de 1968, abolió este requisito.

Por lo que toca a política salarial, los trabajadores colombianos que desempeñan las mismas funciones que los extranjeros, en una empresa o institución, tienen el derecho a exigir una remuneración y condiciones de trabajo iguales.

El código laboral también dice que "no puede haber ninguna diferencia salarial por razón de edad, nacionalidad, raza, religión, opiniones políticas o actividades sindicales".

Los principios anteriores están incluidos en casi toda la Legislación Latinoamericana y fueron proclamados en el tratado de Versalles, cuando se estableció la política de igual remuneración para trabajo igual.

\section{B. Porcentajes de empleos de alta capacitación llenados por extranjeros}

Según el censo demográfico nacional de 1964, la población económicamente activa, fue la siguiente: el $99.36 \%$ nacionales y el $0.64 \%$ extranjeros. En cifras absolutas, el censo indicó que habían 74.053 extranjeros en Colombia, principalmente de las siguientes nacionalidades: Venezuela, Estados Unidos, Ecuador, España, Brasil y Panamá.

De esta cifra total, 48.961 extranjeros pertenecían a la población económicamente activa pero en realidad apenas 33.129 formaban parte de la fuerza laboral. Se encontró la mayor concentración de personal extranjero en los siguientes campos: servicios, industria, 
comercio y agricultura, las cifras más bajas correspondieron a los siguientes campos: construcción, transporte y servicios públicos.

Se puede considerar extremadamente baja la cuota de la participación extranjera en las actividades económicas nacionales, comparada con otros países latinoamericanos como Argentina, Chile, Uruguay, México, Brasil y Venezuela donde tradicionalmente ha habido un flujo de inmigración más amplio.

Quizás esta situación explica en parte el crecimiento lento del P.N.B. (4.5\%) en los últimos años, pues la participación de los extranjeros en las áreas industriales y agrícolas es relativamente baja y estos niveles son los que contribuyen a un porcentaje más alto en la formación de la riqueza nacional. En Colombia hay 467.336 personas con un nivel educativo intermedio y 71.263 personas con un nivel más alto; o sea, el $10.4 \%$ de la fuerza laboral total.

\section{GRAFICA No. 4 \\ EMPLEOS ESPECIALIZADOS OCUPADOS POR EXTRANJEROS}

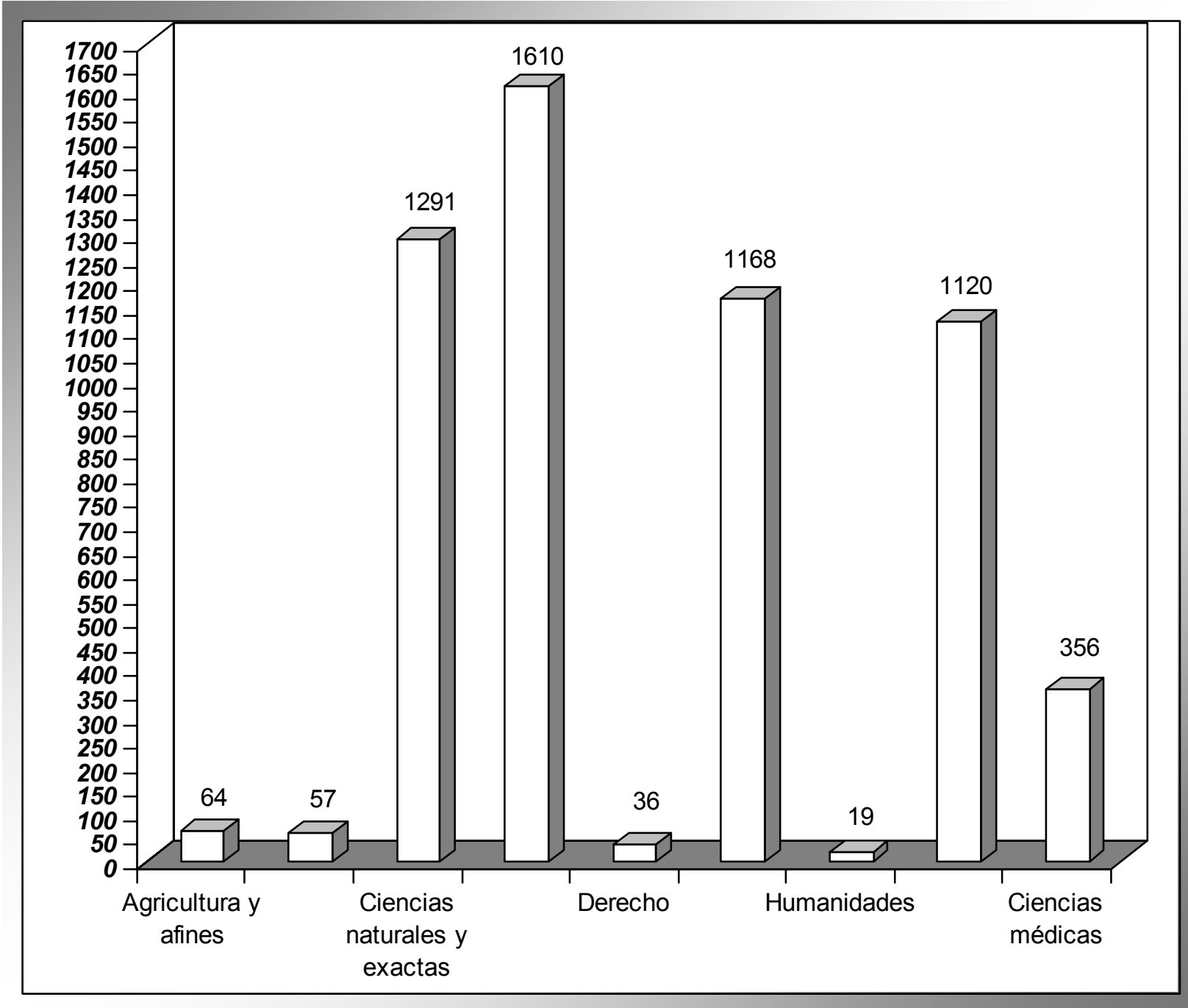


La oficina de inmigración colombiana mantiene un registro preciso de los inmigrantes extranjeros y ésta indica que 4.730 , o sea el $0.8 \%$, son profesionales. Se puede apreciar esta distribución según las diversas áreas de actividad en la gráfica No. 4.

El porcentaje de extranjeros que participan en la fuerza laboral nacional es extremadamente bajo, $0.64 \%$, al compararlo con la población total. En cambio, el porcentaje de la fuerza laboral profesional es bastante alto (aproximadamente el $14 \%$ ). Este hecho llega a ser relevante en el análisis de las categorías ocupacionales de la fuerza laboral colombiana, según la encuesta adelantada en 1964 por el ICETEX con una muestra altamente representativa. La pirámide ocupacional, indica que solo el $8.9 \%$ de la fuerza de trabajo corresponde al nivel profesional.

La información que se presenta en la Gráfica No. 4, empleos de alta capacitación realizados por extranjeros, confirma el hecho de que la contribución de la fuerza laboral extranjera en los dos principales sectores de la actividad económica (industria y agricultura) es bastante baja.

\section{Porcentaje de la fuerza laboral independiente}

Una de las formas para determinar la utilización adecuada de los recursos humanos en Colombia consiste en evaluar la aplicación de los conocimientos para satisfacer las necesidades de la sociedad. Algunos profesionales se dedican al servicio público, otros al sector privado y el resto decide trabajar por su cuenta.

Según el último censo de empleados públicos, hay más de 200.000 empleados públicos, de los cuales 19.000 corresponden al nivel profesional; o sea aproximadamente el $26 \%$ del total de la fuerza laboral profesional. Hay predominio de médicos; siguen los ingenieros civiles, y el resto de las profesiones tienen cabida en el sector público puesto que el Gobierno es el mayor empleador. Por lo tanto se puede asumir que cerca del 71.6 $\%$ de la fuerza laboral profesional en Colombia trabaja con el sector privado, se auto emplea, no practica su profesión o está sujeto a la llamada movilidad profesional.

Se puede analizar este fenómeno de una manera relativamente sencilla; al estudiar los resultados del censo demográfico de 1964. La fuerza laboral profesional informó sobre sus actividades profesionales y se encontró que el $65 \%$ ejercía su profesión ver gráfica No. 5.

Entretanto, el gobierno ha estado canalizando su actividad económica a través de flexibles medidas monetarias y fiscales para aumentar los niveles de empleo público y privado. Además, se discuten varias medidas complementarias como las siguientes:

a) Incentivos fiscales para las compañías que crean programas generales de entrenamiento para sus empleados. 
PRACTICA PROFESIONAL EN COLOMBIA

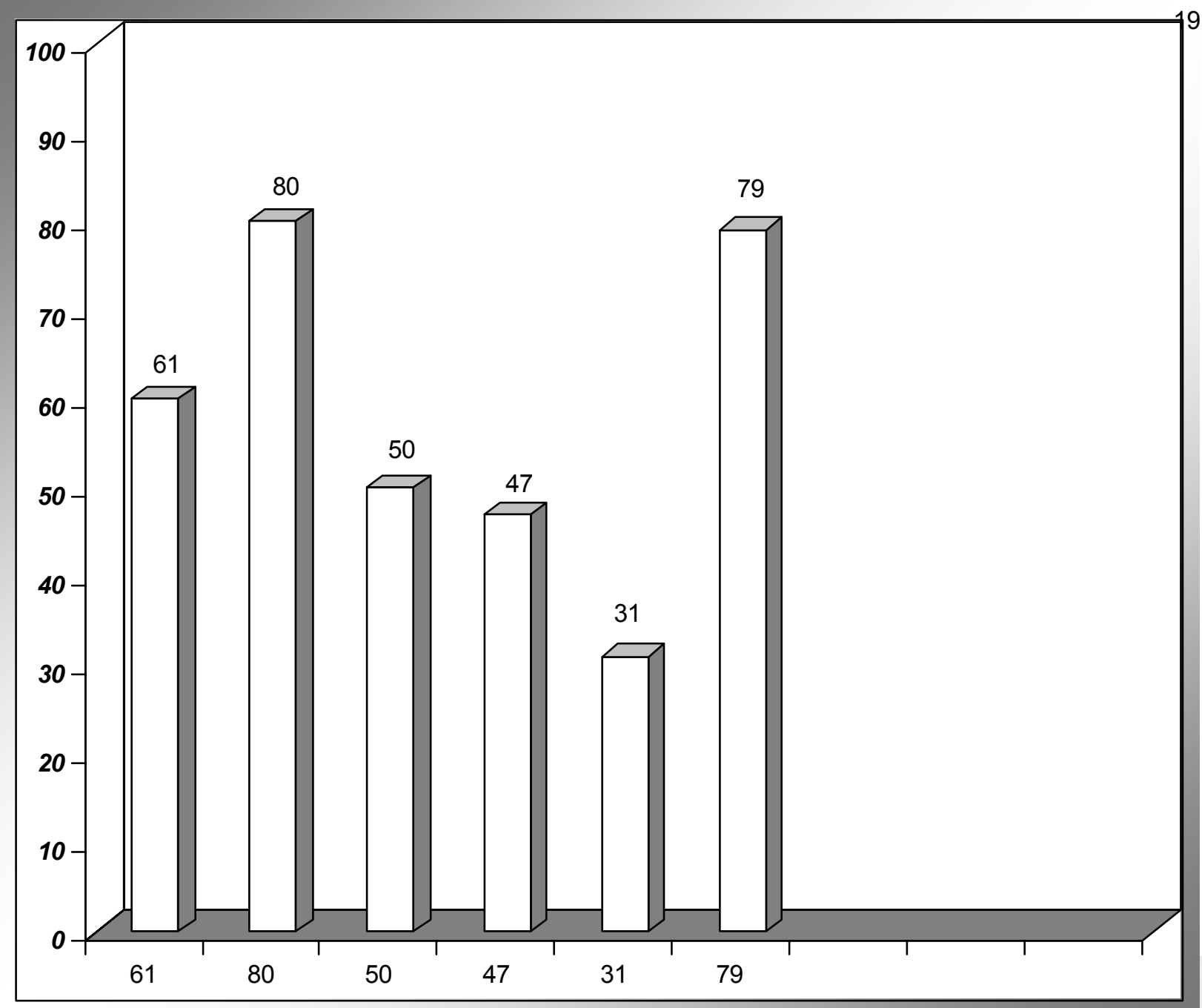

b) Una mayor inversión en la educación a través del presupuesto gubernamental.

c) La redistribución de los ingresos a través de la Reforma Agraria.

d) La invención y adaptación de nuevas tecnologías que son rentables económicamente y requieren trabajo intensivo.

e) La invención y adaptación de nuevas tecnologías que requieren la clase de fuerza laboral disponible en el país para evitar distorsiones y embotellamientos causados por la falta de una fuerza laboral calificada. También, mayores recursos al Instituto de Fomento Industrial (IFI) para promover y estimular la creación de industrias orientadas a generar una mayor demanda de empleo.

Un análisis ocupacional del sector industrial clarifica los esfuerzos y cambios resultantes que están en camino para la generación de más empleo en el sector privado. En el Cuadro No. 17 se indica que la tasa de crecimiento es solamente negativa, en los cinco campos siguientes: la industria tabacalera, 3.7\%; muebles de madera, $0.3 \%$; el caucho, el 
$5.1 \%$; los sub-productos del petróleo y el carbón, el $0.9 \%$; y las industrias metálicas básicas, el $2.8 \%$.

Cuadro No. 17

\section{INCREMENTO ANUAL PROMEDIO DE EMPLEO Y VALOR AGREGADO EN LAS INDUSTRIAS DE TRANSFORMACION}

(1957 - 1968)

\begin{tabular}{|c|c|c|c|}
\hline Campo industrial & $\begin{array}{l}\text { Incremento en el } \\
\text { empleo }\end{array}$ & $\begin{array}{l}\text { Incremento del valor } \\
\text { agregado }\end{array}$ & $\begin{array}{c}\text { Incremento del } \\
\text { empelo } \\
\text { Incremento del valor } \\
\text { agregado }\end{array}$ \\
\hline Alimentos & 2.3 & 8.8 & 0.26 \\
\hline Bebidas & 4.1 & 8.1 & 0.51 \\
\hline Tabaco & -3.7 & 0.8 & -4.63 \\
\hline Textiles & 2.2 & 5.0 & 0.44 \\
\hline Calzado y ropa & 1.1 & 5.1 & 0.22 \\
\hline Productos de madera y corcho & 0.7 & 8.7 & 0.08 \\
\hline Muebles de madera & 0.3 & 3.6 & -0.08 \\
\hline Papel & 10.9 & 35.4 & 0.29 \\
\hline Artes graficas & 3.2 & 7.4 & 0.43 \\
\hline Cuero & 0.2 & 4.2 & 0.05 \\
\hline Caucho & -5.1 & 10.9 & -0.47 \\
\hline Químicos & 7.2 & 18.1 & 0.43 \\
\hline Productos derivados del petróleo & -0.9 & 4.6 & -0.20 \\
\hline Minerales no metálicos & 3.7 & 9.7 & 0.38 \\
\hline Industrias metálicas básicas & 2.8 & 4.0 & -0.70 \\
\hline $\begin{array}{l}\text { Productos metálicos excepto } \\
\text { maquinaria y equipo de transporte }\end{array}$ & 13.6 & 27.1 & 0.50 \\
\hline Maquinaria no eléctrica & 12.6 & 24.9 & 0.51 \\
\hline $\begin{array}{l}\text { Manufactura de maquinaria y } \\
\text { artículos eléctricos }\end{array}$ & 18.8 & 38.7 & 0.48 \\
\hline $\begin{array}{l}\text { Manufactura de } \text { materiales } \\
\text { transporte }\end{array}$ & 5.2 & 9.7 & 0.54 \\
\hline Miscelánea & 10.2 & 21.2 & 0.48 \\
\hline Total & 3.6 & 9.2 & 0.39 \\
\hline
\end{tabular}

Fuente: DANE. 


\section{Cuadro No. 18 \\ DEMANDA Y OFERTA DE PERSONAL PROFESIONAL 1968}

\begin{tabular}{|l|c|c|}
\hline Años de estudio & Demanda \% & Oferta \% \\
\hline Ingeniería y afines & 43.0 & 26.8 \\
\hline Ciencias sociales & 28.1 & 24.2 \\
\hline Agricultura y afines & 9.5 & 10.4 \\
\hline Ciencias naturales y aplicados & 8.1 & 11.7 \\
\hline Educación & 7.3 & 4.8 \\
\hline Derecho & 1.6 & 4.3 \\
\hline
\end{tabular}

Fuente: Servicio de empleo del ICETEX.

En estas industrias hubo una sustitución marcada de trabajo por capital, pero hubo un aumento para los otros 15 campos de actividad industrial. Entre estos últimos los aumentos más significativos fueron de la maquinaria y aparatos eléctricos, con un aumento del $19 \%$ y el de la producción de la maquinaria no eléctrica, con un aumento del $13 \%$.

En términos generales, la tasa de empleo productivo en Colombia aumenta a un ritmo más bajo que el crecimiento del P.N.B.; el $2 \%$ versus el $4.5 \%$.

Por lo tanto los puntos básicos de la problemática del empleo están siendo integrados en los planes generales de desarrollo. Además hay una nueva División de Empleo y Recursos Humanos dentro del Ministerio de Trabajo, cuya función primordial es la de formular una política de empleo y encontrar la mejor manera de utilizar el potencial humano del país.

De acuerdo con esta política, el ICETEX estableció un servicio de empleo para los colombianos que se especializaron en el exterior. Su experiencia indica que la demanda de la fuerza laboral profesional es potencialmente más alta que la oferta actual, como se muestra en el Cuadro No. 18.

En un estudio hecho por el Departamento Administrativo de Planeación, en junio de 1969, se estableció una tipología de las empresas según su dinamismo para aumentar su nivel de empleo. La primera categoría correspondió al grupo menos dinámico en la siguiente forma: alimentos, bebidas, textiles, calzado, prendas de vestir, productos de madera y corcho, minerales no metálicos, excluyendo a los sub-productos del petróleo y carbón y la manufactura de materiales de transporte. Durante el período analizado, las compañías pusieron un limite sobre el crecimiento de empleo entre el $0 \%$ al $5.9 \%$. En los casos de aumento del valor agregado, se consideraron limites entre el $0 \%$ y el $12.9 \%$.

La segunda categoría de industrias intermedias correspondió al limite que fluctúa entre el $6 \%$ y el $11.9 \%$, en términos del crecimiento del nivel de empleo, y entre el $13 \%$ y el $25.9 \%$ para el crecimiento del valor agregado. Se incluyeron las siguientes industrias: papel y productos similares, substancias y productos químicos, y artículos manufactureros varios.

La tercera categoría correspondió a las industrias más dinámicas. Su crecimiento de empleo correspondió al $12 \%$ o más y el crecimiento del valor agregado fue del $26 \%$ o 
más. En esta categoría se incluyeron a las industrias de productos metálicos (excluyendo maquinaria y equipos de transporte), maquinaria no-eléctrica y electrodomésticos. Para la formación de la tipología indicada, cuando no coinciden las categorías de las dos variables, se determina la clasificación por la tasa de crecimiento de empleo.

Basándose en los datos anteriores, se puede concluir que hay hechos que permiten el desarrollo de un programa más racional para la utilización de los recursos humanos del país, junto con la participación y apoyo de las organizaciones privadas. Aunque esto es un hecho, todavía falta una política definitiva para lograr una coordinación de esfuerzos más armónica entre el sector público y privado. 